\title{
Semidiurnal tides in the Laptev Sea Shelf zone in the summer season
}

V. Fofonova, ${ }^{1,2}$ A. Androsov, ${ }^{2}$ S. Danilov, ${ }^{2}$ M. Janout, ${ }^{2}$ E. Sofina, ${ }^{3,4}$ K. Wiltshire ${ }^{1}$

${ }^{1}$ The Alfred Wegener Institute, Helmholtz Centre for Polar and Marine Research, Coastal Ecology, Kurpromenade, D-27498 Helgoland, Germany.

${ }^{2}$ The Alfred Wegener Institute, Helmholtz Centre for Polar and Marine Research, Climate Dynamics, Bussestrasse 24, D-27570 Bremerhaven, Germany.

${ }^{3}$ St. Petersburg Branch, Shirshov Institute of Oceanology, Russian Academy of Sciences, Pervaya Linia 30, 199053 St. Petersburg, Russia.

${ }^{4}$ Russian State Hydrometeorological University, Malookhtinskii 98, 195196 St. Petersburg, Russia.

Vera.Fofonova@awi.de, Alexey.Androsov@awi.de, Sergey.Danilov@awi.de, Markus.Janout@awi.de, sofjina k@mail.ru, Karen.Wiltshire@awi.de.

\begin{abstract}
Tidal processes play an important role in the dynamics of shelf circulation in the Laptev Sea. The Unstructured Grid Finite Volume Coastal Ocean Model (FVCOM) is used to simulate the tidal dynamics in the Lena Delta region of the Laptev Sea in ice-free barotropic case. The grid element size is ranging from $400 \mathrm{~m}$ to $5 \mathrm{~km}$. The major semidiurnal tidal waves $M_{2}$ and $S_{2}$ are investigated with the $M_{2}$ being the most important in generating large sea level amplitudes and currents over the shallow areas. A correction to the tidal elevation at the open boundary is proposed which minimizes the discrepancy between the model prediction and observations. The observations include both recent mooring data and the standard set of tide gauge measurements used in previous studies. The comparison of results to known tidal solutions is carried out. The paper also discusses the residual circulation and energy fluxes and assesses the impact of additional bathymetric information.
\end{abstract}

\section{Keywords}

Laptev Sea; Semidiurnal tides; FVCOM; Arctic Shelf; Lena Delta 


\section{Introduction}

The south-eastern part of the Laptev Sea, which includes the Lena Delta region, represents a large, shallow, estuarine area with dominant depths of about 10-30 m and complex shape of the coastline (Fig. 1). It forms a unique, plankton and zoobenthos rich, arctic ecosystem, characterized by high productivity supported by a powerful Lena River discharge (Sorokin and Sorokin , 1996).

A large number of observations available for the Lena Delta region suggest significant changes both in climatology and in ecosystem over the last fifty years (AARI, web source; Bauch et al., 2009; Costard et al., 2007; Dmitrenko et al., 2008a; Hölemann et al., 2011). Given the large territory, the direct measurements are by far insufficient, calling for a modeling approach which would enable one to estimate the impact of different factors on the circulation dynamics and would lay the foundation for further ecosystem modeling. Tidally driven currents and mixing are important factors of such modeling.

Tides provide direct forcing to the Arctic marginal seas in all seasons (Lenn et al., 2011). The topographic features of the south-eastern part of the Laptev Sea make it very sensitive to tidallyinduced mixing that dominates over the eastern Siberian Shelf (Kowalik and Proshutinsky, 1994; Munk and Wunsch, 1998; Sofina, 2008). Tides may have a strong impact on marine ecosystems. The strong density contrast between the surface and bottom water would lead to reduced oxygen in the bottom layer if not the turbulent transport due to strong tidal currents over shallow water regions (Müller, 2008). The residual currents of barotropic motion play an important role in the transport of sediment, nutrients and organic matter in lagoons and estuaries, namely, in their exportation toward coastal seas (Valentim et al., 2013). For this reason, proper modeling of tidal dynamics is a prerequisite of any modeling efforts in the shelf part of the Laptev Sea.

While there are numerous modeling studies devoted to the dynamics of the Arctic Ocean, studies with focus on the coastal part of the Laptev Sea are virtually absent. In the Arctic the amplitudes of semidiurnal $M_{2}$ and $S_{2}$ and diurnal $K_{1}$ and $O_{1}$ tidal waves dominate over all tidal constituents (Kowalik and Proshutinsky, 1994). Numerical models simulating these constituents for the Arctic Ocean (AO) and its subdomains (e.g., Chen et al., 2009; Kowalik and Proshutinsky, 
1993, 1995; Lyard, 1997) reveal that increased resolution helps to more accurately reproduce currents amplified over varying topography. Whereas the Russian Arctic coast zones, and the Laptev Sea in particular, are getting more and more in the spotlight, the still insufficient amount of observational data as well as the lack of modeling efforts with fine resolution over the shelf leaves many challenges. However, certain observational evidence has already been accumulated, leading to valuable insights in tidal dynamics (Dmitrenko et al., 2012; Janout and Lenn, 2013; Lenn et al., 2011).

The goal of this paper is to study the tidally driven circulation in the shelf zone of the Laptev Sea with focus on the Lena Delta region in ice-free barotropic case. We concentrate on the semidiurnal tidal waves $M_{2}$ and $S_{2}$, which will be simulated separately. The contribution from $M_{2}$ is the most important in the region, followed by $S_{2}$. According to AOTIM5 and TPXO7.1 (Padman and Erofeeva, 2004), the amplitude of the next largest semi-diurnal constituent $N_{2}$ is approximately 2-3 times smaller than amplitude of $S_{2}$ constituent on the open boundary of our region. The observations by Janout and Lenn, 2013 show a weak velocity signal of lunar elliptical tide $N_{2}$ only in the outer shelf area of the Laptev Sea. We therefore do not take it into account. The contribution of the $K_{1}$ and $O_{1}$ constituents in the domain is negligible based on observational data (Dmitrenko et al., 2012; Janout and Lenn, 2013).

Special attention is paid to the choice of open boundary conditions (OBC) for the tidal elevation for the investigated constituents. The OBC play the main role in achieving good agreement with observations in the limited modeling domain. It turns out that conditions derived from available global or Arctic solutions have to be corrected, and we describe the procedure used. We also address in detail questions of energy balance and residual currents and carry out a comparison with available observations and model results. The model used for our studies is the Finite Volume Coastal Ocean Model (FVCOM), which has a solid record of practical applications (Chen et al., 2006; Rego and Li, 2010; Zhao et al., 2006) and works on unstructured meshes allowing variable resolution. 
To validate the performance of the model we used data of tide gauges and moorings. Their locations are shown in Fig.1 superimposed on the bathymetry map of the domain under consideration. The comparison with accurate inverse solutions for AO and World Ocean AOTIM5, TPX06.2 and TPXO7.1 (Padman and Erofeeva, 2004) and tidal simulations for AO (Chen et al., 2009) and Siberian Shelf (Kagan et al., 2008a) has been also carried out.

The paper is organized as follows: In the next section we briefly describe data and model solutions we will use for comparison. Section 3 presents the description of our model and solutions used to impose boundary conditions on the model open boundary. In section 4 we present and discuss tidal maps simulated for the $M_{2}$ and $S_{2}$ waves, which prove to be in a good agreement with observations, and also comparison with other simulations. We analyze ellipses of barotropic currents and the residual circulation induced by the $M_{2}$-tide. We extend the analysis further and consider the energy balance for the $M_{2}$ and $S_{2}$ waves and the sensitivity to the bathymetry. Section 5 presents the conclusion.

\section{Available solutions and data}

\subsection{Tidal solutions}

In this subsection we briefly describe tidal solutions for Global and Arctic Oceans and also for the Siberian Shelf, which will be used for comparison and to construct the OBC for tidal elevation. They include inverse solutions obtained by assimilating data of tide gauges and satellite altimetry (TPX06.2, TPXO7.1 and AOTIM5) and two solutions of forward 3D models for the Siberian Continental Shelf and Arctic Ocean.

We begin from the inverse models. The AOTIM5 (The Arctic Ocean Tidal Inverse Model) is based on Egbert et al., 1994 data assimilation scheme and presents an inverse solution with all available tide gauge data in the Arctic Ocean (Padman and Erofeeva, 2004). The Arctic Ocean Dynamics-based Tide Model (the numerical solution to the shallow water equations) was used as a 'prior' solution. This pan-Arctic 2-D linear model employs a 5-km regular grid and simulates 4 the most energetic tides constituents $\left(M_{2}, S_{2}, O_{1}\right.$ and $\left.K_{1}\right)$. Assimilated data consist of coastal and 
benthic tide gauges, between 250 and 310 gauges per tidal constituent, and also of available satellite altimetry data (Padman and Erofeeva, 2004). Model bathymetry is based on the International Bathymetric Chart of the Arctic Ocean (Jakobsson et al., 2008). AOTIM5 does not consider the effect of sea ice.

The TPXO7.1 and TPXO6.2 are global inverse tide models (Egbert et al., 1994; Padman and Erofeeva, 2004). The resolution of these models is $1 / 4^{\circ} \times 1 / 4^{\circ}$. The TPXO7.1 and TPXO 6.2 assimilate TOPEX/Poseidon (T/P) and TOPEX Tandem satellite radar altimetry (available for the ice-free ocean between $+/-66^{\circ}$ latitude), and in situ tide gauge data in the Antarctic and the Arctic. The TPX07.1 is considered as one of the most accurate global tidal solutions and recommended for using as a global model by Egbert, Erofeeva and Padman (EP).

Chen et al., 2009 presented the high-resolution unstructured grid finite-volume Arctic Ocean model (AO-FVCOM) with application for tidal studies. The horizontal resolution is ranging from $1 \mathrm{~km}$ in the near-coastal areas to $15 \mathrm{~km}$ in the deep ocean. The domain is divided into 40 sigmalayers. This model accurately resolves the irregular geometry of bays, inlets and islands in the Arctic coastal zone. But it shows rather large amplitude and phase differences between the modeled and observed semidiurnal tides along the Siberian Coast.

Kagan et al., 2008a,b and Sofina, 2008 presented the tidal model of the Siberian Continental Shelf (Kara, Laptev, East-Siberian and Chukchi Seas) based on a modified 3D finite-element hydrostatic model QUODDY-4. The ocean is considered homogeneous. The horizontal resolution varies from $2.57 \mathrm{~km}$ near the shore to $60.66 \mathrm{~km}$ in the open ocean. The water column is divided into 20 sigma-layers. Tidal elevation at the open boundary is determined by tidal forcing from the AOTIM5. The model takes into account the backward effect of shore-fast and drifting ice on the tidal dynamics. A comparison with observations on tidal gauges on the Siberian Continental Shelf of modeled tidal amplitudes and phases in the absence of sea ice shows smaller root mean square absolute and relative errors for this regional model than for the AOTIM5. These results also will be used in our analysis. 


\section{2. Observations}

Observations of tidal currents over the Laptev Sea Continental Shelf are rare and fragmentary. The starting point for our analysis is tide gauge data obtained from http://www.ims.uaf.edu/tide/, the source organized by Kowalik and Proshutinsky (KP). These data are used by KP for verification of their barotropic Arctic tidal model with sea ice (Kowalik and Proshutinsky, 1993,1994,1995). Note that the positions of these tide gauge stations were shifted up to $40 \mathrm{~km}$ for verification of AO-FVCOM by Chen et al., 2009 (see Fig. 1). The Buor-Haya station will be excluded from our analysis because its coordinates as used in Chen et al., 2009, and provided by KP differ by approximately 2 degrees of latitude. In addition, the amphidromic points for the $M_{2}$ and $S_{2}$ constituents are located close to the Buor-Haya station (Sofina, 2008), which leads to the high sensitivity of phase calculation to the position of this station. For our analysis we use coordinates provided by KP with some precision corrections obtained from Permanent Service for Mean Sea Level (PSMSL:http://www.psmsl.org/). We should mention that the large part (about 80\%) of these data came from tide tables published in Russia in 1941 and their quality has never been evaluated and discussed (Chen et al., 2009). The recent research confirmed that significant corrections of amplitudes and phases for coastal stations are needed (Voinov, 2002). It should also be stressed that measurements on these stations can be done only within a couple of months due to presence of fast ice. However these data allow constructing the major pattern of tidal dynamics in the region.

The other set of data we will use for analysis is based on several year-round oceanographic mooring records at different locations, designed to monitor currents and hydrography on the central Laptev Sea Shelf (Janout and Lenn, 2013). Based on these data, Janout and Lenn, 2013 (under revision) computed ellipse parameters of barotropic currents during the sea ice and open water seasons. Their results of barotropic tidal ellipses are based on vertically averaged ADCP profiles. Janout and Lenn, 2013 aimed to investigate the role of stratification on tidal structures, and in turn the importance of the sheared tidal currents on diapycnal mixing. But they also confirmed the theoretical study (Polyakov, 1994) that tidal kinetic energy in the domain considered 
is quantified sufficiently well by the barotropic tide. The moorings were operated as part of the German-Russian "Laptev Sea System" project since 1992. Each mooring was designed to remain at a safe distance below the sea ice, and was equipped with upward-looking Teledyne-RDI Workhorse Sentinel Acoustic Doppler Current Profilers (ADCP, $300 \mathrm{kHz}$ ), moored $\sim 3 \mathrm{~m}$ above the bottom with a sampling frequency of 30 minutes and some moorings were equipped with an additional downward-looking 1200 kHz ADCP (Janout and Lenn, 2013).

For our analysis we choose five different locations (Fig. 1), which are situated in the selected region, and limited to the case of open water.

\section{Model, input data and experiment descriptions}

\subsection{Model description}

For simulations of tidal dynamics in the Delta Lena region of the Laptev Sea we use the Finite Volume Coastal Ocean Model (FVCOM), which solves primitive equations on unstructured meshes (Chen et al., 2006). The computational domain covers water depths up to 65 m (Fig. 1), with the minimum depth set to $1 \mathrm{~m}$. The domain was selected so as to avoid amphidromic points in the close vicinity of its open boundary (we relied on the results by Kagan et al., 2008a and Sofina, 2008), to be large enough to incorporate the central part of the Laptev Sea Shelf zone, yet small enough to keep moderate the ratio of largest to smallest elements of the grid. Simulations are performed on a high quality unstructured grid, which allows us to take into account the complexity of coastline and bathymetry. The grid was generated using the algorithm by Persson and Strang (Persson and Strang, 2004) and is composed of triangles that are close to equilateral. Elements sizes vary from $400 \mathrm{~m}$ near the coast to $5 \mathrm{~km}$ in the deepest area of the domain. The number of nodes in each horizontal layer is about 250000; the mesh contains 6 vertical sigma-layers. We use equally spaced sigma layers. Additional simulations with not equally spaced sigma layers have been also carried out, but with a smaller time step. We did not find any significant difference in dynamics in these cases. For vertical and horizontal mixing simulation we use the modified Mellor and Yamada level 2.5 and Smagorinsky turbulent closure schemes respectively. The multiplicative 
coefficient in the Smagorinsky parameterization is set to 0.005 . FVCOM uses upwind implementation of momentum advection, so that large values of horizontal viscosity are not necessarily needed. As advection scheme, we apply the second order upwind scheme. The model used in this study employs the mode splitting method. The time step for external mode is $4.6 \mathrm{sec}$, the ratio of internal mode time step to external mode time step is 10.

To avoid errors due to the inconsistency between the character of equations and the specified open boundary conditions (prescription of tidal elevation only), a sponge layer has been introduced. It gradually turns off the advection of momentum and viscosity in the vicinity of the open boundary. After series of experiments we decided to use $70-\mathrm{km}$ sponge layer to avoid instabilities in the vicinity of the open boundary and preserve the tidal dynamics inside the domain.

\subsection{Input data}

We used two sources of bathymetry data: GEBCO_08 (The General Bathymetric Chart of the Oceans) gridded bathymetry data - a global 30 arc-second dataset (GEBCO, web source) and data in the vicinity of the Lena Delta consisting of 27686 points from digitized Soviet map provided by Paul Overduin, with an average distance between the points of $800 \mathrm{~m}$. The latter data set is utilized in the analysis of the sensitivity of tidal simulations to the details of bottom topography. For coastline construction, we combined the coastline derived from GEBCO bathymetry data with $\sim 2 \mathrm{~km}$ resolution, which is largely consistent with the bathymetry, but lacks many details at the coast, and NOAA (The National Oceanic and Atmospheric Administration) coastline data with $250 \mathrm{~m}$ resolution from World Vector Shoreline database (NOAA, web source), which is too detailed for the mesh resolution we intended to use. The resolution of coastline obtained by us varies from $400 \mathrm{~m}$ to $800 \mathrm{~m}$, depending on the local size of mesh elements. The GEBCO data, because of their smooth character, do not allow one to take into account certain essential coastline features. We, therefore, departed from the NOAA data removing, first, fragments with a too small local curvature radius (given by the minimum triangle side) and relaxing the coastline toward the smooth GEBCO data. Thus, for each local region an optimization problem was solved. In the end, to further smooth the coastline we used cubic b-splines technique. Fig. 2 illustrates the 
result, which is close to both data sets where the coastline is smooth, but shows deviations over the intended part of the boundary.

\subsection{Open boundary conditions derivation and experiment description}

Specification of tidal elevation on the open boundary is central to modeling tides (we do not take the tidal potential into account because the model includes a rather long open boundary). It turned out that the amplitudes and phases of the elevation on the open boundary, taken from the inverse solutions, should be corrected near the coast (depth<10-15 m). For one thing, the inverse solutions predict different dynamics in the region of interest, as illustrated in Fig. 3. Indeed, the amplitude maps provided by these solutions differ substantially on the model open boundary, especially over the western part. The horizontal resolution of TPX06.2 and TPXO7.1 and associated inaccuracies in assumed bathymetry data limit the skill of their solutions in the coastal zone. Although AOTIM5 provides much better spatial resolution, it is still insufficient. Based on the available solutions, we tried to combine and adjust them at the open boundary so that the simulated elevation inside the domain reaches best possible agreement with the available observational data. We have 10 stations where the observed amplitudes and phase are available and also 5 stations with the information about barotropic ellipse parameters in the region considered. The information from 3 stations can be used directly because they are close to the open boundary. The rest can be taken into account indirectly, by doing simulations and analyzing their results. In a way, it was a simplified version of data assimilation procedure.

We used a two-step procedure to find the optimal boundary conditions (OBC). First, we derived the tidal elevation from the available inverse solutions of AOTIM5, TPXO6.2 and TPX07.1, and analyzed to what a degree each of them leads to an accurate solution. For each of three cases of OBC, with the tidal elevation taken from AOTIM5, TPX06.2 or TPXO7.1, the bottom drag coefficient was tuned to reach the best agreement with observations. The bottom drag coefficient varies with depth as given by the second formula in the section describing user- 
defined setting in Chen et al., 2006. We slightly modified the bounds in this formula. The maximum and minimum of the bottom drag coefficient were chosen for each case of OBC.

On the second step, we, first, split the open boundary in segments (Fig. 1) and analyzed the impact of each of them on the amplitude and phase patterns. Carrying out numerous experiments, we selected the solutions on each segment that provided the best agreement with observations. They have been then additionally corrected by directly taking into account the information from the tide gauges situated near the open boundary, and further tuned then to improve the agreement with observational data at other locations. As a result we designed the corrected tidal elevation for the $M_{2}$ and $S_{2}$ constituents on the open boundary. Some other details will be provided below.

\section{Results and Discussion}

Our analysis will touch several aspects of tidal circulation. First, we present and discuss the simulated tidal maps and parameters of barotropic ellipses, comparing them against the available solutions and observations, and also the residual circulation. Next we will examine the impact of improved topography representation, which predict small, but systematic shift in tidal map, and will end with the discussion of energy balance and energy fluxes in the analyzed domain.

\subsection{Tidal maps and parameters of barotropic ellipses}

We begin the description from experiments forced directly by TPX06.2, AOTIM5 and TPX07.1. The best results for the $M_{2}$ constituent were obtained for OBC derived from TPXO7.1, with the bottom drag coefficient varying in the range from 0.003 to 0.005 . Simulation with the OBC from AOTIM5 with the bottom drag coefficient varies in the range from 0.001 to 0.003 have nearly the same quality. The simulations based on TPX06.2 boundary conditions are characterized by the largest phase errors compared to simulations based on TPXO7.1 and AOTIM5. This result implies that for semidiurnal tides, AOTIM5 and TPX07.1 provide a significantly better fit to the tide gauge data than TPXO6.2 (Padman and Erofeeva, 2004) for the $M_{2}$ constituent (Table 1). We observe that tidal dynamics simulated with $\mathrm{OBC}$ from any of inverse models as well as direct 
predictions of these models are markedly different in the south-western part of the domain for both $M_{2}$ and $S_{2}$ tidal waves. It is by all probability explained by bathymetry features in that zone (Figs. 1, 7), which were either not taken into account or not resolved in the AOTIM5, TPX07.1 and TPX06.2. Note also that this region in all these models is too deep.

In order to construct an optimal OBC for the $M_{2}$ constituent we used the amplitudes and phases from TPX07.1, but with a slightly reduced amplitude, as the zeroth-order approach. It allowed us to reduce the bottom friction coefficient to 0.001 to 0.003 and, respectively, to use the AOTIM5 data for a near coast correction. The correction was selected so as to optimize the agreement of simulated elevation with the observed amplitudes and phases near all open boundary segments (stations 1, 5, 6, 7, 9, 10 (Fig.1)). The TPXO7.1 was used as a base for optimal OBC, because the results of experiment forced directly by TPXO7.1 provide better agreement with known ellipses parameters in five positions (Fig. 1), compare to the results of experiment forced by AOTIM 5. The results of our simulations for the amplitudes and phases for the $M_{2}$ constituent are summarized in Table 1. The information on vector error is shown in Fig. 4. They indicate that a substantial improvement in agreement with observations is achieved for the amplitude at nearly all stations in case with optimal OBC. The last column in Table 1 and the rightmost bars in Fig.4 relate to our attempt to improve the agreement between our simulation and observations by slightly displacing the positions of observational points. We sought for position within $20 \mathrm{~km}$ radius where the simulated results agree better with observations (note that Chen et al., 2009, assumed even larger displacements). As it can be seen, the agreement can be significantly improved, which clearly reflects the impact of simulated positions of amphidromic points on the overall accuracy.

In Table $1 E r_{A}=\sqrt{\sum_{i=1}^{N}\left(A_{S}(i)-A_{O}(i)\right)^{2}}$ is the error of amplitude in the Euclidean norm $\left(L^{2}-\right.$ norm), where $A_{S}$ is the simulated amplitude and $A_{O}$ the observed amplitude. $E r_{P}=\frac{1}{N} \sum_{i=1}^{N} D_{P}(i)$ is

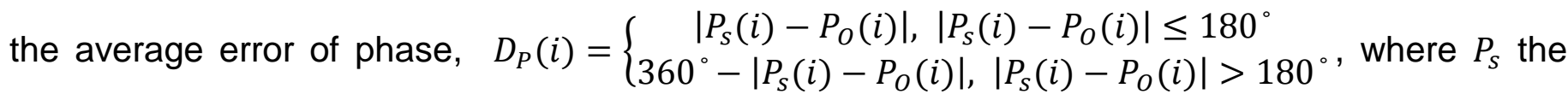


simulated phase, $P_{O}$ the observed phase, $P_{S}, P_{O} \in\left[0,360^{\circ}\right]$ and $N=10$ the number of stations. The error of phase is in $L^{1}$-norm (divided by $\mathrm{N}$ ) for the convenience of calculation.

The ordinate in Fig. 4 is the average error for both phase and amplitude (RMS vector error) computed as Error $=\frac{1}{N} \sum_{i=1}^{N}\left(\left(1+\left(\frac{A_{S}(i)}{A_{O}(i)}\right)^{2}-2 \cdot \cos \left(\frac{P_{S}(i)-P_{O}(i)}{2}\right) \cdot \frac{A_{S}(i)}{A_{O}(i)}\right)^{\frac{1}{2}}\right)$.

The tidal map for the $M_{2}$ constituent with the optimally corrected $\mathrm{OBC}$, providing the best agreement with observations, is presented in Fig. 5a. The $S_{2}$ constituent was treated in the same way. The optimal OBC for it were designed based on the same principles. Our simulated tidal map for the $S_{2}$ wave is shown in Fig. 5b. With exception for a degenerate amphidromic point in the $S_{2}$ case near the Lyakhovsky Islands (Fig. 2), other amphidromic points occupy close locations in cases of the $M_{2}$ and $S_{2}$ waves. Accordingly the Kelvin wave is a dominant factor in forming amphidromic points for both $M_{2}$ and $S_{2}$ constituents.

The results of comparison for the $S_{2}$ constituent with other models are presented in Fig. 4. For the $S_{2}$ wave, the data on M. Bykovsky station are not available and the analysis is based on 9 stations. Note that in all cases in Fig. 4 the error for the $S_{2}$ slightly exceeds that for $M_{2}$ tide.

The simulated tidal map for the $M_{2}$ constituent (Fig. 5a) has many features in common with the empirical tidal map shown in Dvorkin, 1970 and also with modeling results from Androsov et al., 1998; Chen et al., 2009; Dvorkin et al., 1972; Kagan et al., 2008a; Kowalik and Proshutinsky, 1994; Lyard, 1997; Padman and Erofeeva, 2004; Polyakov, 1994. It includes a "chain" of cyclonic amphidromes located near the coast. This picture can be explained with the Poincare waves originating from oblique reflection of the Sverdrup waves from the coast followed by an interference of the incident and reflected ones (Androsov et al., 1998; Nekrasov, 1990) with predominantly eastward propagating waves. The tidal waves with large amplitudes enter the region from the western part (Fig. 5a) of the open boundary fragment A (Fig. 1). They travel as the Kelvin waves along the coast, the contour lines of phase are perpendicular to the coastline (Fig. 5a). On their way they lose much of their energy and only a small portion reaches the East Siberian Sea through the Dmitry Laptev Strait (Fig. 2). We should emphasize that the positions of 
amphidromic points number 4 and 5 (Fig. 5a) directly depend on the condition on the open boundary segments $\mathrm{C}$ and $\mathrm{B}$ (Fig. 1). The position of amphidromic point number 3 (Fig. $5 \mathrm{a}$ ) is the most stable and largely coincides in all considered models. The amphidromic point number 1 can be degenerate or even disappear depending on conditions in the south-western part of the open boundary $A$. The amphidromic point number 2 depends on the condition in the western part of the open boundary A and can move far to the west, if amphidromic point number 1 is not present.

The positions and directions of rotation of phase around amphidromic points are similar to modeling results provided by Kagan et al., 2008a and Chen et al., 2009, except for the apmhidromic point near the Aerosiemka and Samolet Islands (Fig. 2), which is not presented in these models. The numbers and positions of amphidromic points in our domain differ between our simulations and solutions of AOTIM5, TPX06.2 and TPXO7.1. All they provide less amphidromes compared to Chen et al., 2009; Kagan et al., 2008a, and tidal maps obtained by us. The AOTIM5 provides the closest picture to the obtained tidal maps but with essentially different positions of the amphidromes. Due to this reason, the attempt to improve the agreement with observations by assuming that stations locations are shifted within some radius is not as efficient for the inverse tidal solutions as it was for AO-FVCOM, for example.

The ellipses of barotropic currents for the $M_{2}$ constituent are shown in Fig. 6 and the residual circulation for the western part of our domain is shown in Fig. 7.

In most areas the major axes of barotropic ellipses are less than $10 \mathrm{~cm} \mathrm{~s}^{-1}$, but on the periphery of islands they can reach up to $50 \mathrm{~cm} \mathrm{~s}^{-1}$. The most powerful is the western part of the domain, where amplitudes and major axes of barotropic ellipses are maximal (Fig. 6), which is in agreement with (Sofina, 2008). In general, the ellipses with clockwise rotation dominate in the region, as confirmed by the observations (Janout and Lenn, 2013) and modeling study (Padman and Erofeeva, 2004; Sofina, 2008). In the deepest part of the domain (depth $>25 \mathrm{~m}$ ) the tidal current ellipses are nearly circular: the minor-to-major axis ratio may be as large as 0.9 , the zones of change in the rotation direction are the exception. 
The residual currents are mainly shaped by bathymetric features and the Coriolis force (Fig. 7). Far from the shore the residual circulation has a vortex structure, the residual currents are also localized along coastal boundaries. Maximum residual currents $\left(10 \mathrm{~cm} \mathrm{~s}^{-1}\right)$ are reached on the periphery of islands. In general, residual currents are smaller than $2 \mathrm{~cm} \mathrm{~s}^{-1}$. The residual circulation in the eastern part of considered domain, which is not shown in Fig. 7, is much weaker than in the western part. Only motion along coastal boundaries remains before Selyahskaya Guba (Fig. 2), where it forms a vortical flow.

We now discuss how the ellipse parameters in different models compare with observational data. The results are summarized in Table 2. Unfortunately, we did not have any information about ellipse parameters from the AO-FVCOM and Siberian Shelf model, so only inverse solutions will be considered in addition to the simulated one. The sense of rotation is provided by the sign of the minor axis, with the negative sign implying the clockwise (anticyclonic) rotation.

In Table $2 E r_{a x e s}$ is the error of major (minor) axes in the Euclidean norm, $E r_{a v}$ the arithmetic average of the $E r_{\text {axes_min }}$ and $E r_{\text {axes_min }}$.

For different OBC our model provides better agreement with major axes observations compared to all Arctic Ocean barotropic models respectively (Table 2, Fig. 8). It generally predicts a larger minor axis, but with the correct sign, than measured and obtained directly from different Arctic Ocean barotropic models, the same effect was shown by Chen et al., 2009. We tried to improve the agreement with observational data reported in Janout and Lenn, 2013, by varying the bottom drag coefficient. However, it turned out that the measures to improve the agreement for major axes impair the agreement for the minor axes for all stations, and vice versa.

Noteworthy, our solutions with optimally designed OBC give one of the best arithmetic average of the errors for major and minor axes $\left(E r_{a v}\right)$ for the both $M_{2}$ and $S_{2}$ waves (Table 2). Note that comparably small errors characterize also the results derived directly from TPX06.2 for $M_{2}$ component, directly from AOTIM5 for the $S_{2}$ component and our simulations forced by TPX07.1 solution (Table 2). Also for all our simulations the directions of rotation coincide with observational directions for both components. The exception is the sign of minor axis for the $M_{2}$ 
component at the second station (II) (Fig. 1), which may be due to the proximity to the region with opposite rotation (Fig. 6). The inclinations for all solutions have nearly the same accuracy.

\subsection{Sensitivity to bathymetry}

The agreement of our simulations with observational data is further improved when topography derived from GEBCO is merged with the additional bathymetric data from digitized Soviet map covering the vicinity of the Lena Delta. The upper panel of Fig. 9 shows the modification of topography suggested by this additional data set. Broadly speaking, there is a large-scale pattern with regions that are shallower or deeper on average, but also there are important depth corrections near amphidromic point 2 (Fig. 5a). As follows from panel b, it leads to substantial local corrections.

Using this synthetic bathymetry, in the experiment with the $M_{2}$ constituent the error was reduced by nearly 25 percent (from 0.29 (Fig. 4) to 0.22). We have found that with a more realistic bathymetry the total energy of the system can change significantly.

Numerous studies emphasize the importance of properly selected bottom friction in shallow regions (Lu and Zhang, 2006; Rego and Li, 2010). Our simulations indicate that using OBC derived from the global models (as TPX06.2, TPX07.1) may require to use a larger bottom drag coefficient than in the case when the tidal OBC are derived from regional model (AOTIM5). For assimilated models we can see the next imbalance: if in shallow part of the domain the results for amplitudes and phases have good agreement with observations it can lead to large errors for major and minor axis in neighboring deep regions. Bottom drag, however, cannot be varied in wide limits. In the case considered, increasing the bottom friction coefficient 2.5 times results in the total energy reduction by 35 percent in experiment with the $M_{2}$ component. We continue with the analysis of energy balance. With larger value of bottom friction coefficient the time it takes the system to equilibrate obviously is decreasing. 


\subsection{Energy balance}

The analysis of the energy budget provides an important insight into the evolution of energy in the model region.

The equation of energy for the vertically averaged equations has the form:

(1) $\frac{\partial \bar{E}}{\partial t}+\nabla \cdot\left[\rho \mathrm{H}\left(g \zeta+\frac{1}{2}|\overline{\mathbf{v}}|^{2}\right) \overline{\mathbf{v}}\right]=-\rho r|\overline{\mathbf{v}}|^{3 / 2}+\rho \overline{\mathbf{v}} \cdot(\nabla \cdot(K \mathrm{H} \nabla \overline{\mathbf{v}}))$,

where $\bar{E}=\frac{1}{2} \rho\left(\mathrm{H}|\overline{\mathbf{v}}|^{2}+g \zeta^{2}\right)$ is the total energy per unit area, $\overline{\mathbf{v}}=\int_{-\mathrm{h}}^{\zeta} \mathbf{v} d z$ is the vertically integrated fluid velocity, $\zeta$ the sea surface level, $\mathrm{H}=h+\zeta, h$ the water depth, $\rho$ the water density, $r$ the bottom drag coefficient, $K$ the generally non-uniform eddy viscosity coefficient, $g$ the acceleration due to gravity and $\nabla=\left(\frac{\partial}{\partial x}, \frac{\partial}{\partial y}\right)$ is the gradient operator.

After integration of eq. (1) over the region $\Omega$ with boundary $\partial \Omega=\partial \Omega_{1}+\partial \Omega_{2}, \partial \Omega_{1}$ is the solid part of the boundary, $\partial \Omega_{2}$ the open boundary, taking into account the Gauss and Green formulas for divergence and Laplace operator respectively and condition of zero velocities at $\partial \Omega_{1}$, we obtain the mean energy balance equation:

(2) $\int_{\Omega} \frac{\partial \bar{E}}{\partial t} d x d y=$

$-\int_{\partial \Omega_{2}}\left[\rho \mathrm{H}\left(g \zeta+\frac{1}{2}|\overline{\mathbf{v}}|^{2}\right) \frac{\partial \overline{\mathbf{v}}}{\partial \mathbf{n}}-\frac{1}{2} \rho K \mathrm{H} \frac{\partial|\overline{\mathbf{v}}|^{2}}{\partial \mathbf{n}}\right] d s-\int_{\Omega} \rho r|\overline{\mathbf{v}}|^{3 / 2} d x d y-\int_{\Omega} \rho K \mathrm{H}\left(\left|\overline{\mathbf{v}}_{x}\right|^{2}+\left|\overline{\mathbf{v}}_{y}\right|^{2}\right) d x d y$,

where $\frac{\partial \overline{\mathbf{v}}}{\partial \mathbf{n}}=(\overline{\mathbf{v}} \cdot \mathbf{n}), \mathbf{n}$ is the outward normal to $\partial \Omega_{2}, \overline{\mathbf{v}}_{x}$ and $\overline{\mathbf{v}}_{y}$ the partial derivatives of $\overline{\mathbf{v}}$.

The first term on the right side of (2) is the total flux of energy across the open boundary, the second and third terms are the rates of energy dissipation due to the bottom friction and due to viscosity, respectively (see, e.g., Androsov et al., 1998, 2002).

The Fig.10 shows that the total energy (energy for the whole domain) for the $M_{2}$ component is approximately twice higher than that for the $S_{2}$ component. The result is in agreement with observational data on the Laptev Sea Shelf (Dmitrenko et al., 2008b, 2012). The number of simulated periods was dictated by the time of complete system equilibration. The difference in the total energy between the two last periods is negligible (Fig. 10). There is some asymmetry between the half-periods in Fig. 10, which is linked to the presence of higher harmonics. In the 
western part of the domain, where tidal currents for both $M_{2}$ and $S_{2}$ are strong (Fig. 5), bathymetry features lead to intensification of the nonlinear effects and this is accompanied by asymmetry in the flows over the tidal period. However the asymmetry is quite small in our study. Figure 11 shows the amplitudes of higher harmonics $M_{4}, M_{6}, M_{8}$, compare to the amplitude of $M_{2}$, and constant term $\left(Z_{0}\right)$ at all coastal stations.

Components of the energy equation (2) are presented in Fig. 12 for both $M_{2}$ and $S_{2}$ constituents. The magnitude of the energy budget residual in Fig. 12 is small indicating that the budget is fulfilled with high accuracy in numerical simulations. There is a balance between the temporal change of energy and energy fluxes through the open boundaries during the tidal cycle for both constituents. The horizontal turbulent exchange plays a minor role in energy budget; its contribution is smaller than the contributions of other components of the balance by a factor $10^{4}$. As expected, the contribution of bottom friction is substantial because the fluid layer is relatively shallow over a large part of the computational domain.

Numerical computations generally do not conserve energy unless special measures are undertaken, and FVCOM code is not energy conserving. It has certain numerical viscosity, which is, by all probability, mostly the reason of small imbalance in our energy analysis. Although the imbalance is mostly due to numerical viscosity, it also contains other errors (time stepping, interpolation to the open boundary, etc.). Note however that the mean imbalance is more than 2 orders of magnitude smaller than averaged impact of bottom friction for both constituents considered here, and this is why FVCOM can safely be used for tidal simulations.

The tidal energy flux is estimated using the following definition (Crawford, 1984; Kowalik and Proshutinsky, 1993):

$\left(E_{\lambda}, E_{\theta}\right)=\frac{1}{T} \int_{0}^{T} \rho \mathrm{H}\left(g \xi+\frac{1}{2}|\overline{\mathbf{v}}|^{2}\right) \overline{\mathbf{v}} d t$, where $E_{\lambda}, E_{\theta}$ are the zonal and meridional components of the tidal energy flux vector, $\mathrm{T}$ is the tidal period.

The spatial patterns of energy flux for the $M_{2}$ and $S_{2}$ constituents are close to each other but have their own unique features (Fig. 13). For both $M_{2}$ and $S_{2}$ constituents the tidal energy is largely supplied by the progressive tidal wave propagating to the coastal area from the central northern 
part of the open boundary segment $A$ (the deepest area in our domain) (Fig. 1). An essential part of this energy goes directly to the south and also a significant part of energy leaves the domain little west. Also for both constituents the coastal energy flux comes from the west, but for the $M_{2}$ it is much stronger (Fig. 13). This flux propagates along the shore from the western part of the Laptev Sea, which has the biggest amplitudes (see Fig. 5 and e.g., Kagan et al., 2008a; Padman and Erofeeva, 2004). The $M_{2}$ constituent is characterized by a strong flux from the south-western part of the open boundary, partly deflecting from the region slightly to the south. In the western part of the domain the fluxes from different sides meet, especially for the $M_{2}$ tide, the resultant energy flux vectors have a high level of dissipation due to small depths and topography traps (Figs. 7, 13). As a consequence of the importance of these details, influenced by details in bottom topography, the Arctic Ocean and global tidal models on one hand and our simulations with the OBC derived from these models on the other hand provide different dynamics for the western part of the domain considered here. The zone in the vicinity of Lena Delta is a dissipation region for the $M_{2}$ and $S_{2}$ tides energy. In this region, the paths of the $M_{2}$ and $S_{2}$ tides energy fluxes are controlled by the large amount of small islands, complex coastline topography and intricate bathymetry, with flushing through narrow channels. The eastern open boundaries have only a small impact on the tidal dynamics in the region for the both waves. The high-resolution simulations reveal many mesoscale patterns which vary greatly over the space and types. It is hard to compare in details our energy fluxes with those in (Lyard, 1997), for the horizontal resolution and coastline geometry is different. However, the patterns have much in common. We made comparison with the patterns of energy fluxes by Chen et al. (2009), (their Fig. 8 and 9) and conclude that they agree well.

\section{Conclusion}

The barotropic tidal model for the Lena Delta region of the Laptev Sea established here provides a necessary first step to further modeling of the circulation and ecosystem dynamics in the area. This model accurately resolves the irregular coastal topography with a large number of small islands and narrow channels and also bathymetry features of this domain. It reproduces the 
major semidiurnal tidal waves $M_{2}$ and $S_{2}$, which are the most important in generating large sea level amplitudes and currents over the considered shallow area. For the domain under consideration a special procedure was developed for the construction of optimal OBC for tidal elevation for both components. These $\mathrm{OBC}$ were based on results of modeling studies and observations. The simulated tidal maps show an improved agreement with observations as compared to other modeling studies performed for a larger area. The model also provides important information about barotropic currents, residual circulation, which affects sediment and nutrients transport, and evolution of energy fluxes in the region. The residuals of the energy budget are small implying that the budget is nearly balanced in the numerical simulations.

The next step is to set up a full model for accurate simulation of water stratification and ice in the domain. This is the subject of ongoing work. However, the results obtained here will be relevant in that case too. Indeed, the stratification causes only small variations in the structure of the tidal sea level, especially in the shallow areas like our region (Polyakov, 1995). The tidal kinetic energy in the domain considered is quantified sufficiently well by the barotropic tide, as follows from observations (Janout and Lenn, 2013). However, Janout and Lenn showed a strong link between stratification and baroclinic tidal structures, which of course must be considered when looking into diapycnal mixing processes. The freshwater plume dynamics can in principle modify both the tidal elevation and vertical structure of tidal ellipses. However, the main Lena freshwater channels are in the eastern part of the Lena Delta (carrying about $89 \%$ of the total Lena feshwater to the Laptev Sea (Magritsky, 2001)). The freshwater plume spreads towards the East-Siberian Sea or to the north depending on the atmospheric conditions in the summer (Dmitrenko et al., 2010a). According to the observations (Janout and Lenn, 2013) and our modeling results, the tides are weak in the eastern part of the domain where most of freshwater is directed. This leads us to expect that freshwater plum dynamics will not noticeably interfere with tidal dynamics. A more delicate issue is the impact of sea ice. The Arctic tides are sensitive to the presence of ice cover, and mixing in the Arctic shelf seas depends of sea-ice conditions (e.g. Kowalik and Proshutinsky, 1994; Lenn et al., 2011). In a more general context, the fixed ice cover should increase the 
dissipation, resulting in a general decrease in tidal amplitudes and velocities on the one hand and tidal phase delay on the other hand. It is confirmed by modeling results for the Laptev Sea (Kagan et al., 2008a). However we will concentrate on the period when there is no fast ice or ice is absent at all in the domain considered. Modeling results (Kagan et al., 2008a; Kagan and Sofina, 2010) shows that drift ice causes minor restructuring of tidal maps in the region. The changes in amplitude do not exceed $1-3 \mathrm{~cm}$, which is less than the root mean square of absolute errors of model equal $3.8 \mathrm{~cm}$ in the absence of sea ice when the observations are available.

\section{Acknowledgments}

We are grateful to C. Chen and the MEDM research group (University of Massachusetts, Dartmouth) for graciously sharing the FVCOM code. Many thanks to Paul Overduin, who provided bathymetric data from digitized Soviet map. We also want to thank two anonymous reviewers for their valuable comments. 


\section{References}

1. "Arctic and Antarctic Research Institute" Federal State Budgetary Institution. The current state and variability of the natural environment of the Laptev Sea region as a reflection of global climate processes. http://portalrp.ru/atmosphere-and-hydrosphere-monitoring-2007-2010-projects/tech-02515-11-5080 Last accessed: 30.07.2012 (in Russian).

2. Androsov, A., Liberman, Y., Nekrasov, A., Romanenkov, D., Voltzinger, N., 1998. Numerical Study of the $M_{2}$ Tide on the North Siberian Shelf. Continental Shelf Research 18, pp. 715-738. 3. Androsov, A.A., Kagan, B.A, Romanenkov, D.A., Voltzinger, N.E., 2002. Numerical modelling of barotropic tidal dynamics in the strait of Messina. Advances in Water Resources 25(4), pp. 401-415.

4. Bauch, D., Dmitrenko, I., Kirillov, S., Wegner, C., Hölemann, J., Pivovarov, S., Timokhov, L., Kassens, H., 2009. Eurasian Arctic Shelf hydrography: Exchange and residence time of southern Laptev Sea waters. Continental Shelf Research 29 (15), pp. 1815-1820.

5. Chen, C., Liu, H., Beardsley, R. C., 2003. An Unstructured Grid, Finite-Volume, ThreeDimensional, Primitive Equations Ocean Model: Application to Coastal Ocean and Estuaries. Journal of Atmospheric and Oceanic Technology 20(1).

6. Chen, C., Beardsley, R.C., Cowles, G., 2006. An Unstructured Grid, Finite-Volume Coastal Ocean Model. FVCOM User Manual, second ed. SMAST/UMASSD-06-0602.

7. Chen, C., Gao, G., Qi, J., Proshutinsky, A., Beardsley, R. C., Kowalik Z., Lin H., Cowles G., 2009. A new high-resolution unstructured grid finite volume Arctic Ocean model (AO-FVCOM): An application for tidal studies. J. Geophys. Res. 114, C08017.

8. Costard, F., Gautier, E., Brunstein, D., Hammadi, J., Fedorov, A., Yang, D., Dupeyrat, L., 2007. Impact of the global warming on the fluvial thermal erosion over the Lena River in Central Siberia. Geophys. Res. Lett. 34, L14501.

9. Crawford, W. R., 1984. Energy flux and generation of diurnal shelf waves along Vancouver Island. J. Phys. Oceanogr. 14, pp. $1600-1607$.

10. Dmitrenko, I. A., Kirillov, S. A., Tremblay, L. B., 2008a. The long-term and interannual variability of summer fresh water storage over the eastern Siberian Shelf: Implication for climatic change. J. Geophys. Res. 113, C03007.

11. Dmitrenko, I. A., Kirillov, S. A., Ivanov, V. V., Woodgate, R. A., 2008b. Mesoscale Atlantic water eddy off the Laptev Sea continental slope carries the signature of upstream interaction.

J. Geophys. Res. 113, C07005.

12. Dmitrenko, I. A., Kirillov, S. A., Bloshkina, E., Lenn, Y. D., 2012. Tide-induced vertical mixing in the Laptev Sea coastal polynya. J. Geophys. Res. 117, C00G14.

13. Dvorkin, E.N., 1970. Tides. In: Gakkel, Ya.Ya., Govorukha, L.S. (Eds.), Soviet Arctic. Nauka, Moscow, pp. 191-197 (in Russian).

14. Dvorkin, E.N., Kagan, B.A., Cleshyova, G.P., 1972. The calculation of the tide motions in Arctic Seas. Izvestiya Akademii Nauk SSSR Fiziko Atmosf. Okeana 8, pp. 298-306 (in Russian).

15. Egbert, G.D, Bennett A.F., Foreman, M. G., 1994. TOPEX/Poseidon tides estimated using a global inverse model. J. Geophys. Res. 99, C12, pp. 24821-24852.

16. GEBCO. http://www.gebco.net/data and products/gridded bathymetry data/ Last accessed: 12.03.2013 
17. Hölemann, J., Kirillov, S., Klagge, T., Novikhin, A., Kassens, H., Timokhov, L., 2011. Nearbottom water warming in the Laptev Sea in response to atmospheric and sea ice conditions in 2007. Polar Research 30.

18. Holloway, G. and Proshutinsky, A., 2007. Role of tides in Arctic ocean/ice climate. J. Geophys. Res. 112, C04S06.

19. Jakobsson, M., Macnab, R., Mayer, L., Anderson, R., Edwards, M., Hatzky, J., Schenke, H.W., Johnson, P., 2008. An improved bathymetric portrayal of the Arctic Ocean: Implications for ocean modeling and geological, geophysical and oceanographic analyses. Geophys. Res. Lett. 35, L07602.

20. Janout, M. A., Lenn Y.D., 2013. Semidiurnal tides on the Laptev Sea Shelf based on oceanographic moorings with implications for shear and vertical mixing. Journal of Physical Oceanography (accepted).

21. Kagan, B.A., Romanenkov, D.A., Sofina, E.V., 2008a. Tidal ice drift and ice-generated changes in the tidal dynamics/energetics on the Siberian Continental Shelf. Continental Shelf Research 28 (3), pp. 351-368.

22. Kagan, B.A., Romanenkov, D.A., Sofina, E.V., 2008b. Combined Tidal Ice Drift and IceInduced Changes in the Dynamics and Energy of the Combined Tide on the Siberian Continental Shelf. Oceanology 48(3), pp. 317-326.

23. Kagan B.A., Sofina E.V., 2010. Ice-induced seasonal variability of tidal constants in the Arctic Ocean. Continental Shelf Research 30(6), pp. 643-647.

24. Kowalik, Z. and Proshutinsky A.Yu., 1993. Diurnal tides in the Arctic Ocean. J. Geophys. Res. 98, C9, pp. 449-468.

25. Kowalik, Z. and Proshutinsky, A.Yu., 1994. The Arctic Ocean tides. In: Johannessen, O., Muench, R.D., Overland, J.E., (Eds.), The Polar Oceans and Their Role in Shaping the Global Environment. The Nansen Centenia Volume. Geophysical Monogrophy Series, 85. AGU, Washington, DC, pp. 137-158.

26. Kowalik, Z. and Proshutinsky, A.Yu., 1995. Topographic enhancement of tidal motion in the western Barents Sea. J. Geophys. Res. 100, C2, pp. 2613-2637.

27. Lenn, Y. D., Rippeth, T. P., Old, C. P., Bacon, S., Polyakov, I., Ivanov, V., Hölemann, J., 2011. Intermittent Intense Turbulent Mixed under Ice in the Laptev Sea Continental Shelf. Journal of Physical Oceanography 41 (3), pp. 531-547.

28. Lu, X. and Zhang, J., 2006. Numerical study on spatially varying bottom friction coefficient of a 2D tidal model with adjoint method. Continental Shelf Research 26(16), pp. 1905-1923.

29. Lyard, F.H., 1997. The tides in the Arctic Ocean from a finite-element model . J. Geophys. Res. 102, C7, pp. 15611-15638.

30. Müller, L., 2008. Sauerstoffdynamik der Nordsee, Untersuchungen mit einem dreidimensionalen Ökosystemmodell. Berichte des BSH 43. Bundesamt für Seeschiffahrt und Hydrographie (in German).

31. Munk, W. H. and C. Wunsch, 1998. Abyssal recipes II: Energetics of tidal and wind mixing, Deep Sea Res., Part I, 45, pp. 1977- 2010.

32. NOAA. http://www.ngdc.noaa.gov/mgg/shorelines/shorelines.html Last accessed: 15.03.2013.

33. Nekrasov, A.V., 1990. Energy of the Ocean Tides. Gidrometeoizdat Publishers, Leningrad, pp. 290 (in Russian).

34. Padman, L. and Erofeeva, S., 2004. A barotropic inverse tidal model for the Arctic Ocean. Geophys. Res. Lett. 31. 
35. Persson, P.O., Strang, G., 2004. A simple mesh generator in MATLAB. SIAM Review 46 (2), pp. 329-345.

36. Polyakov, I.V., 1994. The $M_{2}$ tide in Arctic Ocean. The structure of barotropic tide. Meteorology and Hydrology №1, pp.56-68 (in Russian).

37. RosHydromet, http://www.r-arcticnet.sr.unh.edu Last accessed: 30.07.2012.

38. Sofina, E.V., 2008. The simulation of tidal ice drift and ice-related changes in tidal dynamics and energy in Siberian Continental Shelf. Dissertation, Russian State Hydrometeorological University (in Russian).

39. Sorokin, Y.I. and Sorokin, P.Y., 1996. Plankton and Primary Production in the Lena River Estuary and in the South-eastern Laptev Sea. Estuarine, Coastal and Shelf Science 43(4), pp. 399-418(20).

40. Valentim, J.M., Vaz, L., Vaz, N., Silva, H., Duarte, B., Caçador, I. and Dias, J.M., 2013. Sea level rise impact in residual circulation in Tagus estuary and Ria de Aveiro lagoon. Proceedings 12th International Coastal Symposium (Plymouth, England), Journal of Coastal Research, Special Issue 65, pp. 1981-1986.

41. Voinov, G., 2002. Tide and tidal streams, in Polar Seas Oceanography: An Integrated Case Study of the Kara Sea. Springer, pp. $147-214$.

42. Zhao, L., Chen, C., Cowles, G., 2006. Tidal flushing and eddy shedding in Mount Hope Bay and Narragansett Bay: An application of FVCOM. J. Geophys. Res. 111, C10015. 


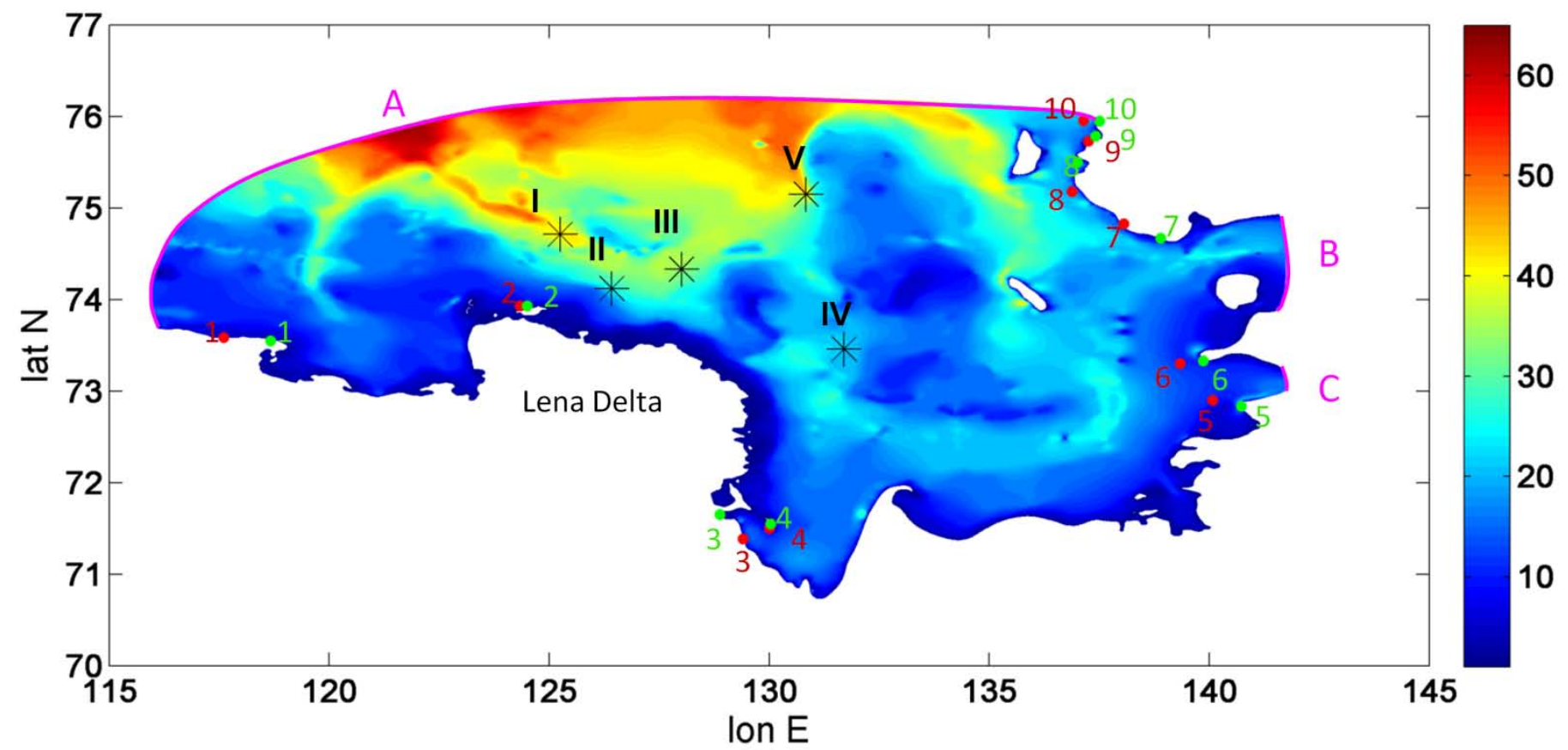

Fig. 1. Bathymetry of the selected domain (derived from GEBCO, resolution $\sim 2 \mathrm{~km}$ ), [m]. The numbered green and red points show the location of tide gauges where the amplitudes and phases are known. The green points correspond to the positions used by KP with some precision correction from the PSMSL data source. The red points are the positions of the stations used for verification AO-FVCOM. They deviate up to $40 \mathrm{~km}$ from the positions provided by KP. The asterisks show the mooring positions with known tidal ellipse parameters. The open boundary segments A, B and C are shown in pink.

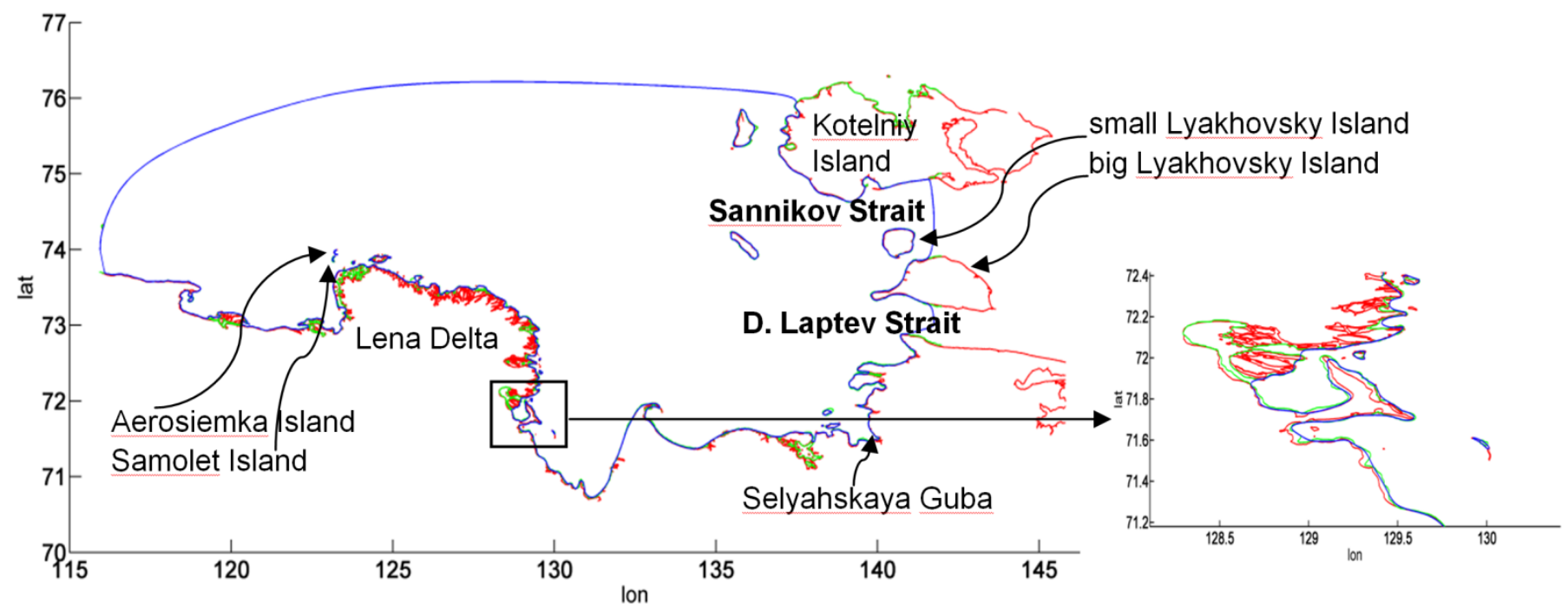

Fig. 2. The coastline of the computational domain. The red line corresponds to the NOAA data, the green one is GEBCO based and the blue one is the used coastline. It is constructed using both datasets, but drawn so as to have bounded curvature (using cubic b-splines), as shown in the right panel for a fragment of coastline. 


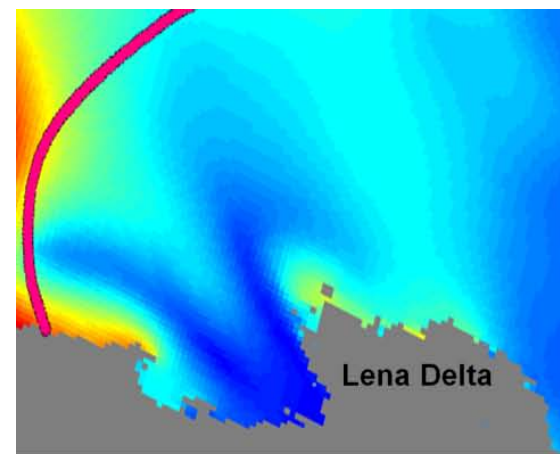

AOTIM5 (5km regular grid)

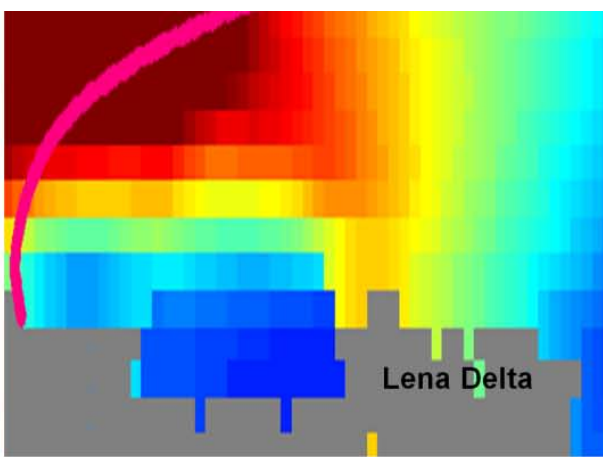

TPX06.2 (1/4 regular grid)

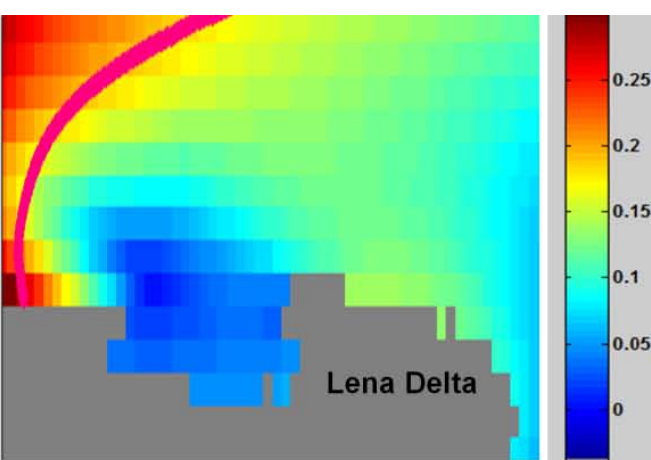

TPX07.1 (1/40 regular grid)

Fig. 3. The amplitude of the $M_{2}$ constituent in the Lena Delta region of the Laptev Sea, [m]. The maps are obtained using TMD toolbox provided by EP. The open boundary is shown in pink.

Table 1. Comparison of amplitudes (Am.) and phases (Ph.) from different models and observational data for the $M_{2}$ constituent. The asterisk indicates the shift in station positions up to $40 \mathrm{~km}$ compare to positions provided by $\mathrm{KP}$, the double asterisk indicates the shift up to $20 \mathrm{~km}$.

\begin{tabular}{|c|c|c|c|c|c|c|c|c|c|c|c|c|}
\hline \multirow{4}{*}{$\begin{array}{c}\text { № } \\
1 \\
1\end{array}$} & \multirow{2}{*}{\multicolumn{2}{|c|}{ Name of station }} & \multicolumn{10}{|c|}{ Amplitude, $\mathrm{cm}\left(M_{2}\right)$} \\
\hline & & & \multirow{2}{*}{$\begin{array}{c}\text { Observ. } \\
14.0\end{array}$} & \multirow{2}{*}{$\begin{array}{c}\begin{array}{c}\text { AO- } \\
\text { FVCOM }^{*}\end{array} \\
15.4\end{array}$} & \multirow{2}{*}{$\begin{array}{c}\begin{array}{c}\text { Siberian } \\
\text { Shelf } \\
\text { model }\end{array} \\
3.1\end{array}$} & \multirow{2}{*}{\begin{tabular}{|c|} 
AOTIM5 \\
18.0
\end{tabular}} & \multirow{2}{*}{\begin{tabular}{|c|} 
TPX07.1 \\
3.2
\end{tabular}} & \multirow{2}{*}{$\begin{array}{c}\text { TPX06.2 } \\
6.3\end{array}$} & \multirow{2}{*}{$\begin{array}{c}\begin{array}{c}\text { Model } \\
\text { forced by } \\
\text { AOTIM5 }\end{array} \\
2.1\end{array}$} & \multirow{2}{*}{$\begin{array}{c}\begin{array}{c}\text { Model } \\
\text { forced by } \\
\text { TPXO7.1 }\end{array} \\
8.0\end{array}$} & \multirow{2}{*}{$\begin{array}{c}\text { Model with } \\
\text { optimal OBC } \\
13.6\end{array}$} & \multirow{2}{*}{$\begin{array}{c}\begin{array}{c}\text { Model with } \\
\text { optimal OBC** }\end{array} \\
14.0\end{array}$} \\
\hline & & Am. & & & & & & & & & & \\
\hline & & $\mathrm{Ph}$. & 24 & 30 & 48 & 41 & 15 & 193 & 325 & 60 & 100 & 24 \\
\hline \multirow{2}{*}{2} & \multirow{2}{*}{ Dunay Isl. } & Am. & 15.0 & 9.5 & 16.0 & 12.6 & 11.4 & 18.5 & 6.4 & 15.6 & 14.2 & 15.0 \\
\hline & & $\mathrm{Ph}$. & 120 & 128 & 125 & 115 & 155 & 144 & 109 & 149 & 124 & 120 \\
\hline \multirow{2}{*}{3} & \multirow{2}{*}{ Tiksi } & Am. & 13.0 & 11.7 & 19.5 & 2.7 & 6.6 & 1.7 & 14.7 & 14.5 & 17.8 & 16.7 \\
\hline & & $\mathrm{Ph}$. & 69 & 40 & 55 & 69 & 46 & 88 & 67 & 98 & 84 & 74 \\
\hline \multirow{2}{*}{4} & \multirow{2}{*}{ Muostakh } & Am. & 13.0 & 9.7 & 16.4 & 1.1 & 6.2 & 1.5 & 12.7 & 12.4 & 15.3 & 13.8 \\
\hline & & $\mathrm{Ph}$. & 36 & 41 & 70 & 15 & 69 & 108 & 63 & 88 & 76 & 58 \\
\hline \multirow{2}{*}{5} & \multirow{2}{*}{$\begin{array}{l}\text { Sviatoy } \\
\text { Nos }\end{array}$} & Am. & 5.0 & 5.3 & 7.2 & 1.2 & 6.0 & 1.5 & 2.1 & 4.0 & 4.6 & 5.0 \\
\hline & & $\mathrm{Ph}$. & 150 & 164 & 157 & 287 & 148 & 306 & 198 & 167 & 158 & 150 \\
\hline \multirow{2}{*}{6} & \multirow{2}{*}{ Kigilliakh } & Am. & 5.0 & 5.1 & 7.3 & 2.1 & 4.3 & 1.8 & 1.8 & 5.0 & 4.8 & 5.0 \\
\hline & & $\mathrm{Ph}$. & 231 & 218 & 149 & 225 & 200 & 208 & 289 & 222 & 222 & 231 \\
\hline \multirow{2}{*}{7} & \multirow{2}{*}{$\begin{array}{c}\text { Sannikova } \\
\text { Pas. }\end{array}$} & $\mathrm{Am}$. & 5.0 & 11.6 & 7.7 & 3.1 & 1.3 & 1.2 & 5.5 & 3.2 & 6.2 & 5.0 \\
\hline & & $\mathrm{Ph}$. & 30 & 18 & 51 & 27 & 15 & 229 & 10 & 29 & 45 & 30 \\
\hline 8 & Kieng & Am. & 7.0 & 9.4 & 12.0 & 9.7 & 7.7 & 7.6 & 7.6 & 8.6 & 9.8 & 7.0 \\
\hline
\end{tabular}




\begin{tabular}{|c|c|c|c|c|c|c|c|c|c|c|c|c|}
\hline & Urasa & $\mathrm{Ph}$. & 111 & 90 & 65 & 91 & 100 & 102 & 69 & 91 & 71 & 84 \\
\hline \multirow{2}{*}{9} & \multirow{2}{*}{ Tempa } & Am. & 15.0 & 20.9 & 18.8 & 16.8 & 13.3 & 14.5 & 12.6 & 12.7 & 14.9 & 15.0 \\
\hline & & $\mathrm{Ph}$. & 93 & 79 & 83 & 80 & 97 & 96 & 55 & 92 & 63 & 75 \\
\hline \multirow{2}{*}{10} & \multirow{2}{*}{ Kotelniy } & Am. & 22.0 & 19.0 & 20.0 & 17.3 & 14.1 & 15.2 & 18.3 & 13.6 & 20.3 & 21.0 \\
\hline & & $\mathrm{Ph}$. & 66 & 69 & 90 & 80 & 95 & 100 & 71 & 94 & 66 & 68 \\
\hline & \multirow{2}{*}{ Error } & \multicolumn{2}{|c|}{$E r_{A}$} & 11.7 & 15.3 & 18.1 & 17.2 & 20.4 & 16.0 & 11.0 & 6.5 & 3.8 \\
\hline & & \multicolumn{2}{|c|}{$E r_{P}$} & 12 & 27 & 24 & 19 & 67 & 31 & 22 & 23 & 7 \\
\hline
\end{tabular}

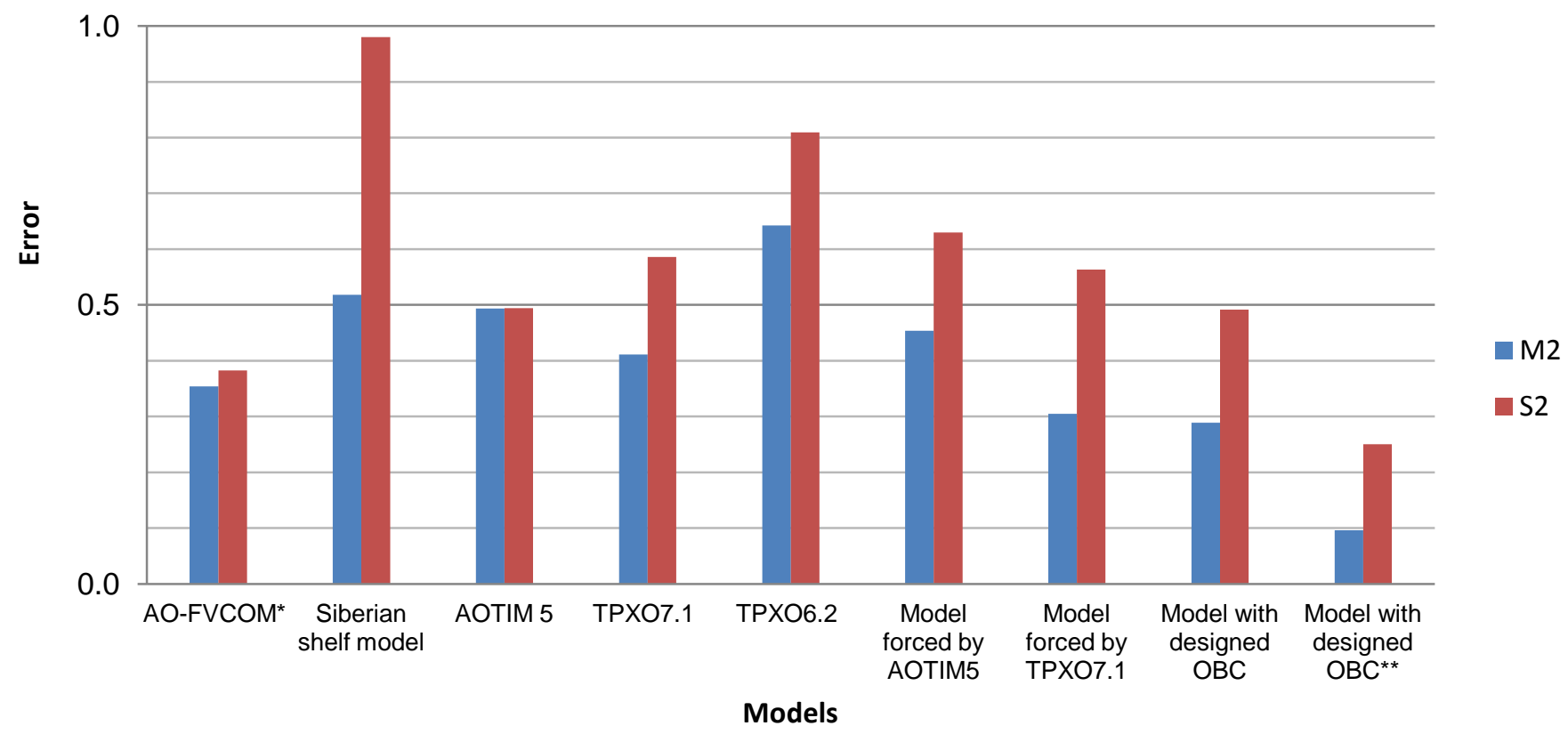

Fig. 4. The error of different models against coastal tide gauges for the $M_{2}$ and $S_{2}$ constituents. The single (double) superscript indicates that points where the simulated results have been taken may deviate up to 40(20) $\mathrm{km}$ from the station positions provided by KP. 
a)
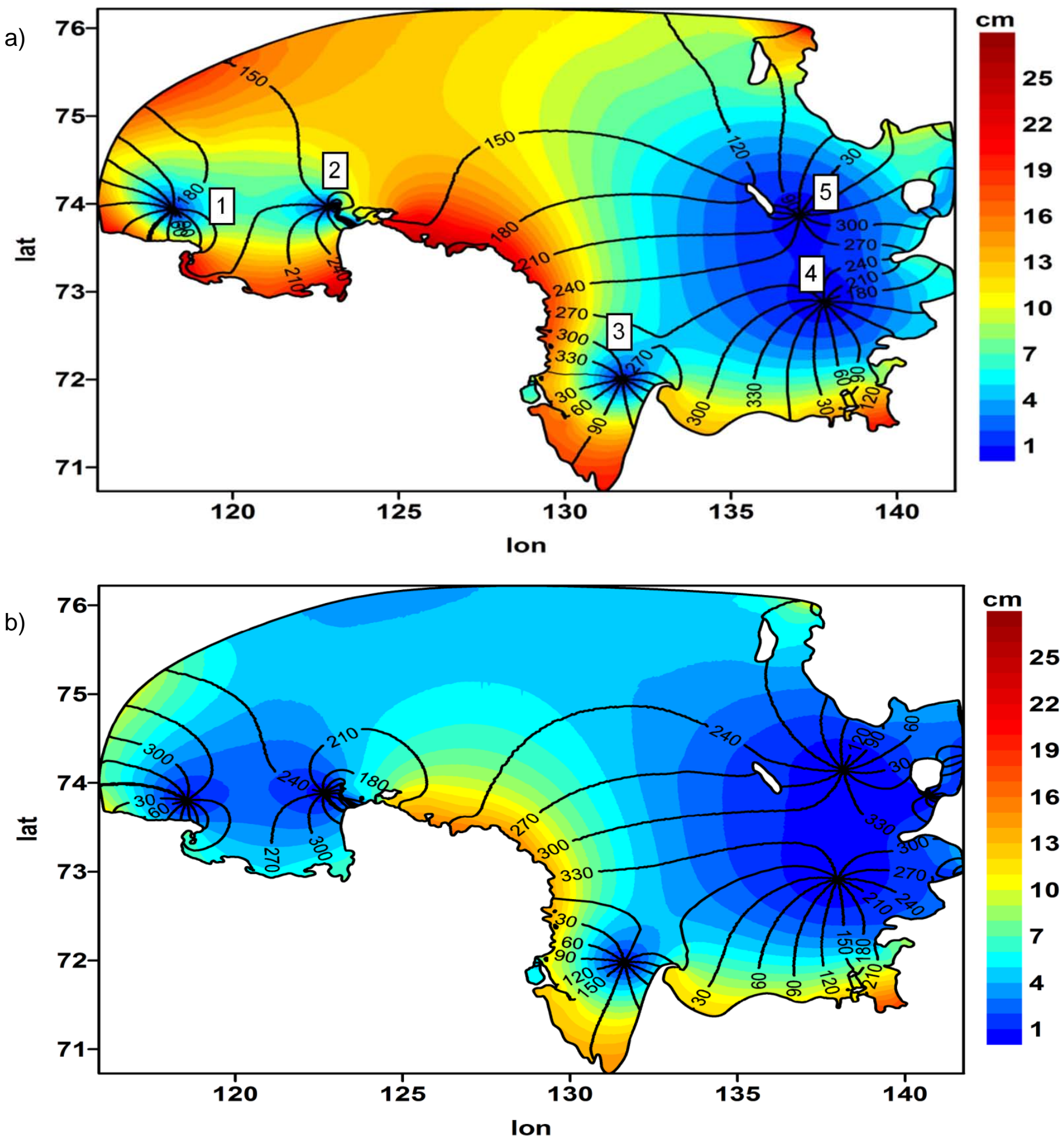

Fig.5. The tidal map for the $M_{2}$ (a) and $S_{2}$ (b) constituents. Simulations use optimal boundary conditions for tidal elevation. 


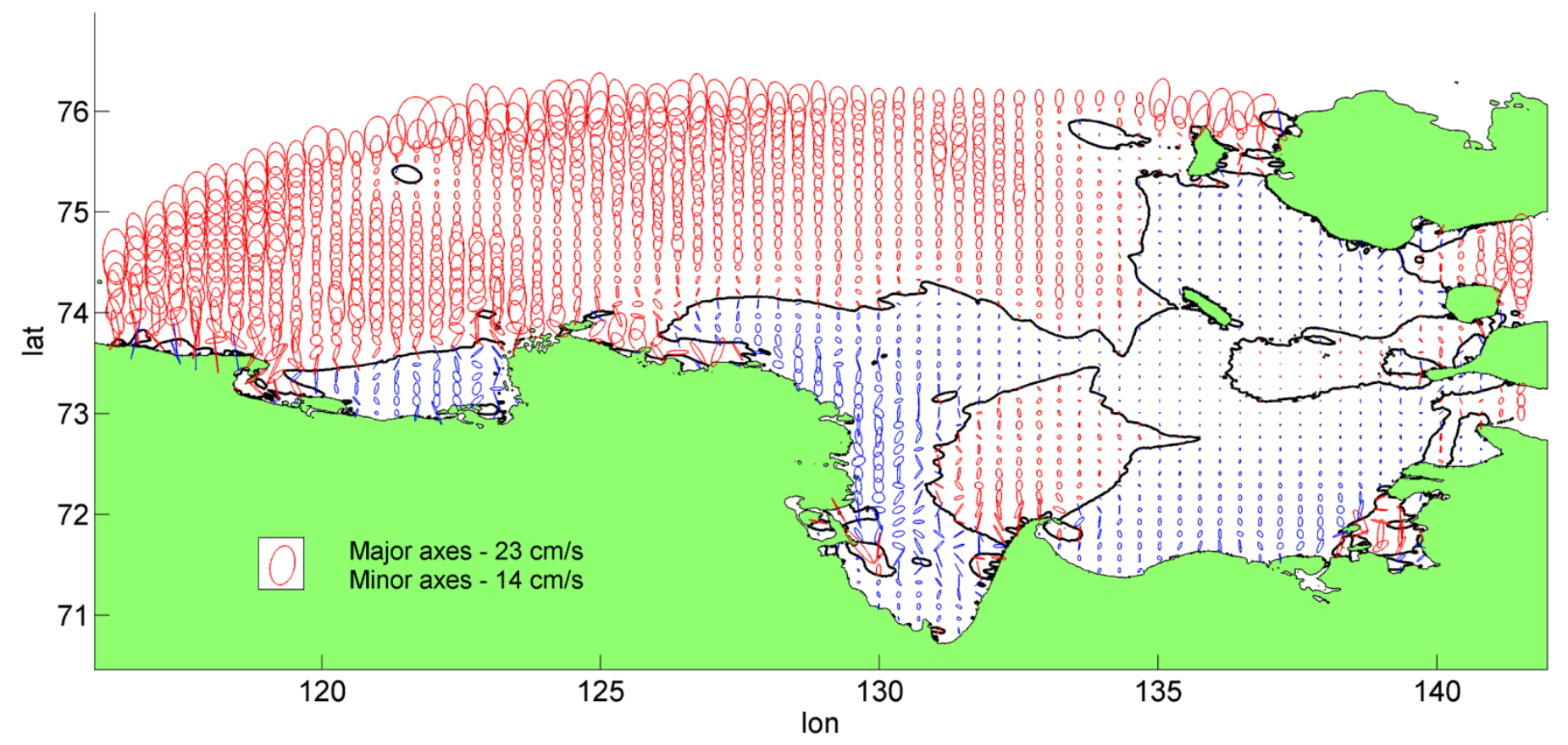

Fig.6. Ellipses of barotropic velocities for the $\boldsymbol{M}_{\mathbf{2}}$ constituent, red ellipses have clockwise rotation, blue ellipses have counterclockwise rotation. The parameters of ellipses are interpolated on a regular grid. The black line marks the change in the rotation direction. Simulations use optimal boundary conditions for tidal elevation.

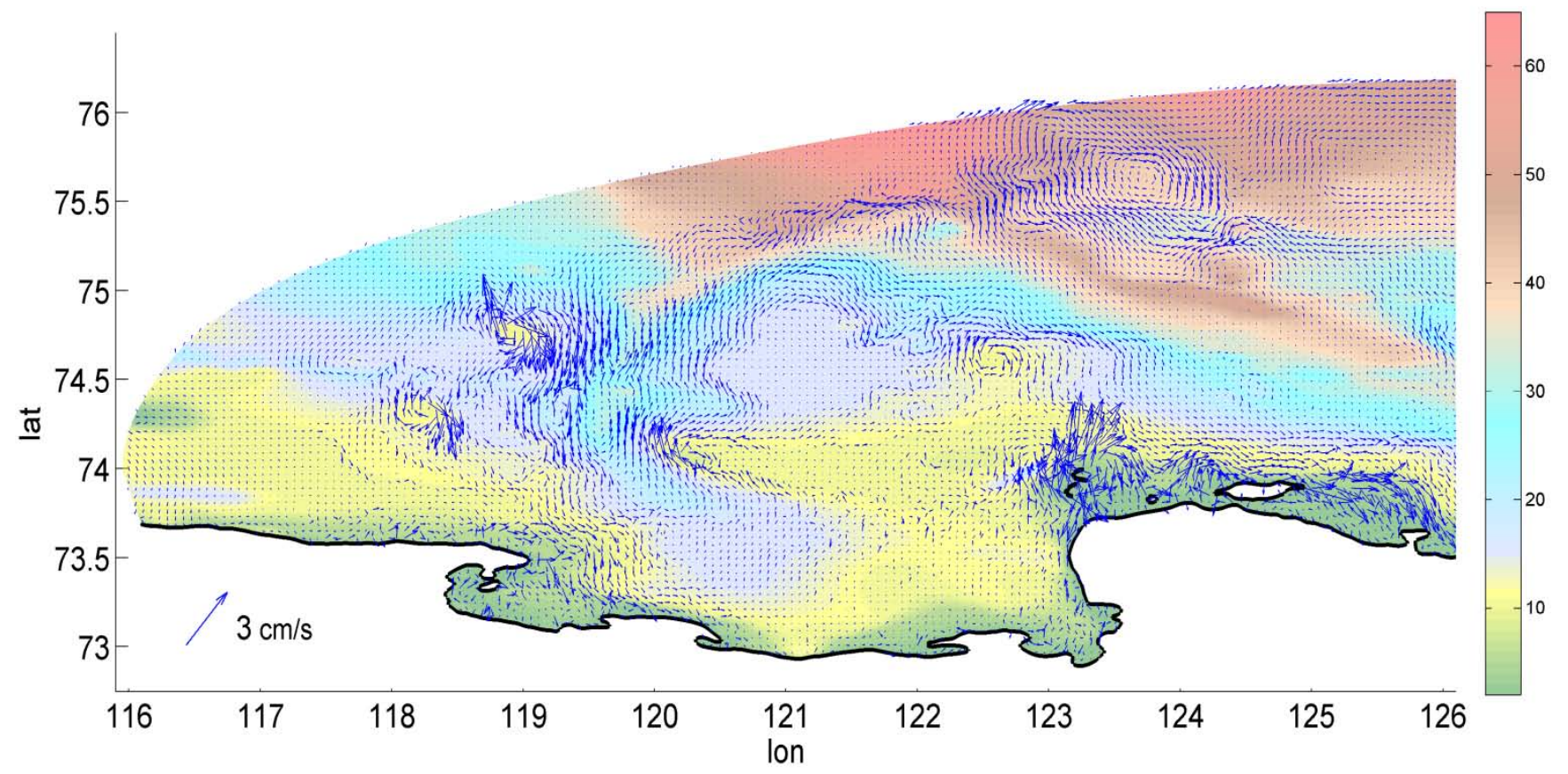

Fig.7. Residual circulation for the $\boldsymbol{M}_{\mathbf{2}}$ constituent superimposed on bathymetry map, [m], for the western part of the considered domain, the vectors are interpolated on a regular grid. Simulations use optimal boundary conditions for tidal elevation. 
Table 2. Comparison of ellipse parameters from different models and observational data in open water season. "Maj." is the abbreviation for the major axes, $M_{2}\left(S_{2}\right),\left[\mathrm{cm} \mathrm{s}^{-1}\right]$, "Min." for the minor axes, $M_{2}\left(S_{2}\right)$, $\left[\mathrm{cm} \mathrm{s}^{-1}\right]$, and "inc." for the inclination, $M_{2}\left(S_{2}\right)$, [deg].

\begin{tabular}{|c|c|c|c|c|c|c|c|c|}
\hline \multirow{2}{*}{\multicolumn{2}{|c|}{ Coordinates of the stations }} & \multicolumn{7}{|c|}{ Major axes, $M_{2}\left(S_{2}\right), c m s^{-1}$} \\
\hline & & \multirow{2}{*}{$\begin{array}{l}\text { Observ. } \\
6.4(2.6)\end{array}$} & \multirow{2}{*}{$\begin{array}{c}\text { AOTIM5 } \\
2.7(1.2)\end{array}$} & \multirow{2}{*}{$\begin{array}{c}\text { TPX07.1 } \\
4.3(2.5)\end{array}$} & \multirow{2}{*}{$\begin{array}{r}\text { TPX06.2 } \\
7.8(3.0)\end{array}$} & \multirow{2}{*}{$\begin{array}{c}\text { Model forced } \\
\text { by AOTIM5 } \\
6.4(5.5)\end{array}$} & \multirow{2}{*}{$\begin{array}{c}\begin{array}{c}\text { Model forced } \\
\text { by TPXO7.1 }\end{array} \\
6.4(3.6)\end{array}$} & \multirow{2}{*}{$\begin{array}{c}\begin{array}{c}\text { Model with } \\
\text { optimal OBC }\end{array} \\
5.3(3.7)\end{array}$} \\
\hline \multirow{3}{*}{$125.2574 .71(\mathrm{I})$} & Maj. & & & & & & & \\
\hline & Min. & $-2.4(-1.4)$ & $-1.2(-0.4)$ & $-3.3(-1.4)$ & $0.01(1.1)$ & $-4.9(-3.6)$ & $-3.8(-2.5)$ & $-4.2(-2.4)$ \\
\hline & Inc. & $84(79)$ & $92(108)$ & 66(95) & $66(78)$ & $140(121)$ & $86(136)$ & $113(130)$ \\
\hline \multirow{3}{*}{12874.33 (III) } & Maj. & $5.6(3.6)$ & $2.8(1.1)$ & $3.5(2.0)$ & $5.2(1.1)$ & $4.4(4.7)$ & $6.3(2.4)$ & $5.5(3.2)$ \\
\hline & Min. & $-0.1(-0.6)$ & $-0.2(-0.2)$ & $-0.9(-0.2)$ & $0.6(0.6)$ & $-2.2(-0.4)$ & $-0.9(-0.4)$ & $-1.2(-1)$ \\
\hline & Inc. & $85(91)$ & $78(91)$ & $68(80)$ & $59(63)$ & $97(91)$ & $72(97)$ & $77(93)$ \\
\hline \multirow{3}{*}{$130.8475 .15(\mathrm{~V})$} & Maj. & $5.4(2.8)$ & $3.9(1.7)$ & $4.8(2.6)$ & $6.7(1.6)$ & $4.8(3.6)$ & $6.2(1.0)$ & $5.5(3.3)$ \\
\hline & Min. & $-1.2(-1.0)$ & $-1.4(-0.7)$ & $-2.7(-1.0)$ & $-1.4(0.2)$ & $-3.3(-1.8)$ & $-2.5(-0.2)$ & $-3.1(-2.7)$ \\
\hline & Inc. & $55(59)$ & $65(69)$ & $58(76)$ & $75(84)$ & $75(79)$ & $64(84)$ & $60(64)$ \\
\hline \multirow{3}{*}{131.7073 .46 (IV) } & Maj. & $3.3(1.3)$ & $1.4(0.7)$ & $1.9(0.6)$ & $1.7(0.6)$ & 3.3(3.3) & $3.2(2.0)$ & $3.4(2.0)$ \\
\hline & Min. & $0.4(0.7)$ & $0.3(0.3)$ & $0.2(-0.1)$ & $0.2(0.1)$ & $0.5(1)$ & $1.6(0.4)$ & $1.6(0.9)$ \\
\hline & Inc. & 115(104) & $126(115)$ & $111(121)$ & $89(103)$ & $110(114)$ & $115(126)$ & 123(112) \\
\hline \multirow{3}{*}{126.4274 .12 (II) } & Maj. & $6.9(4.3)$ & $3.4(1.65)$ & $3.6(2.2)$ & $5.4(1.7)$ & $6.0(7.2)$ & $7.9(3.9)$ & $7.5(4.5)$ \\
\hline & Min. & $0.1(-0.5)$ & $-0.1(0.1)$ & $-1.2(-0.3)$ & $1.3(0.7)$ & $-1.5(-0.1)$ & $-0.3(-0.3)$ & $-0.6(-0.5)$ \\
\hline & Inc. & $26(36)$ & $107(123)$ & $89(99)$ & $72(92)$ & $114(110)$ & 96(115) & 103(98) \\
\hline \multicolumn{3}{|c|}{ Er $_{\text {axes_maj }}$} & $6.3(4.1)$ & $4.7(2.7)$ & $2.9(3.9)$ & $1.6(4.8)$ & $1.5(2.6)$ & $1.4(1.5)$ \\
\hline \multicolumn{3}{|c|}{$E r_{\text {axes_min }}$} & $1.2(1.3)$ & $2.3(0.9)$ & $2.8(3.3)$ & $4.2(2.4)$ & $2.4(1.5)$ & $3.2(2)$ \\
\hline \multicolumn{3}{|c|}{$E r_{a v}$} & $3.75(2.7)$ & $3.5(1.8)$ & $2.85(3.6)$ & $2.9(3.6)$ & $1.95(2.05)$ & $2.3(1.75)$ \\
\hline
\end{tabular}



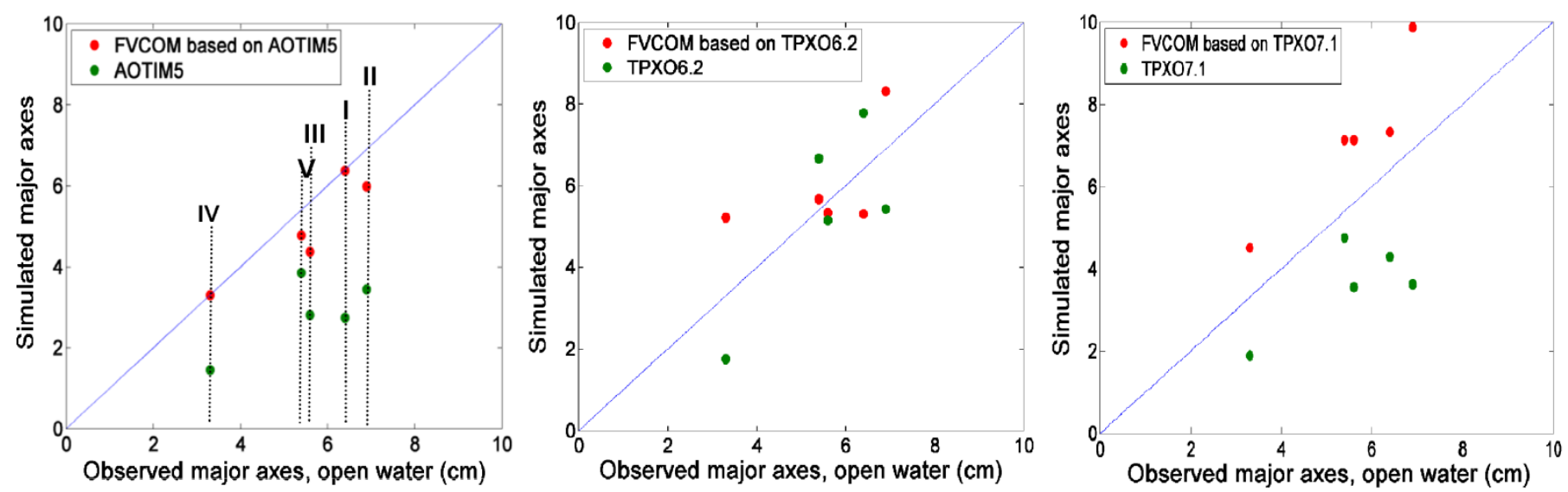

Fig. 8. Comparison of major axes in simulations based on the open boundary conditions from different inverse models and predicted directly by these models with observational data.

a)

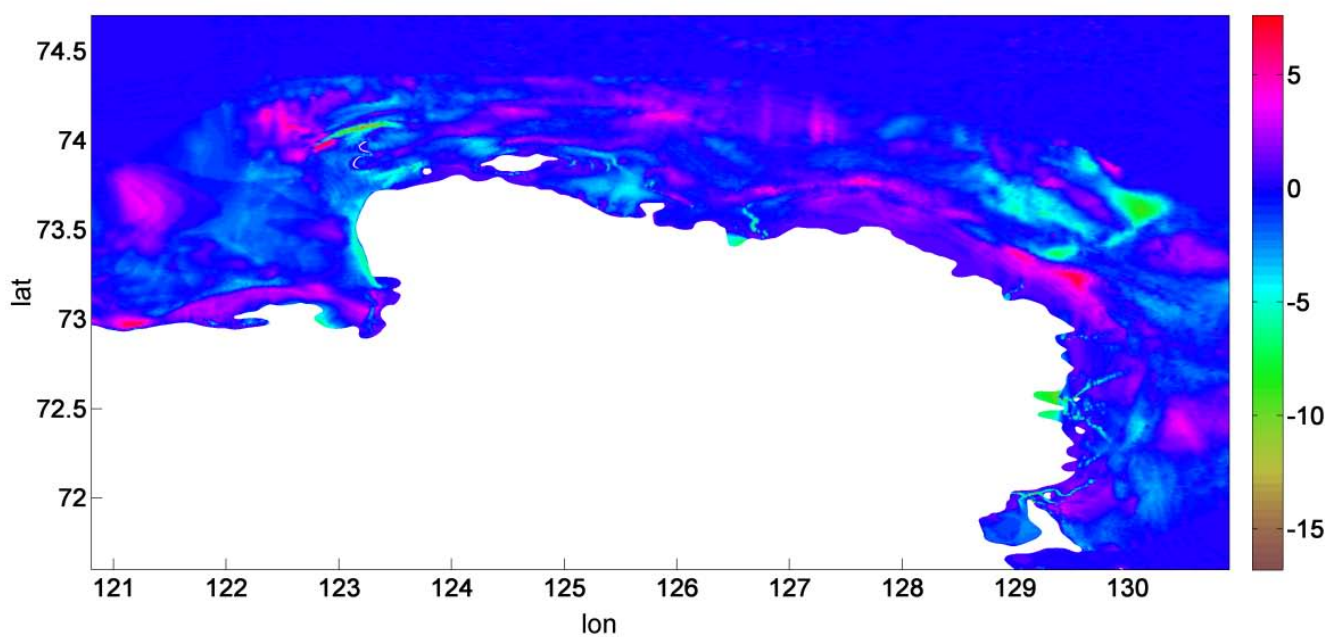

b)

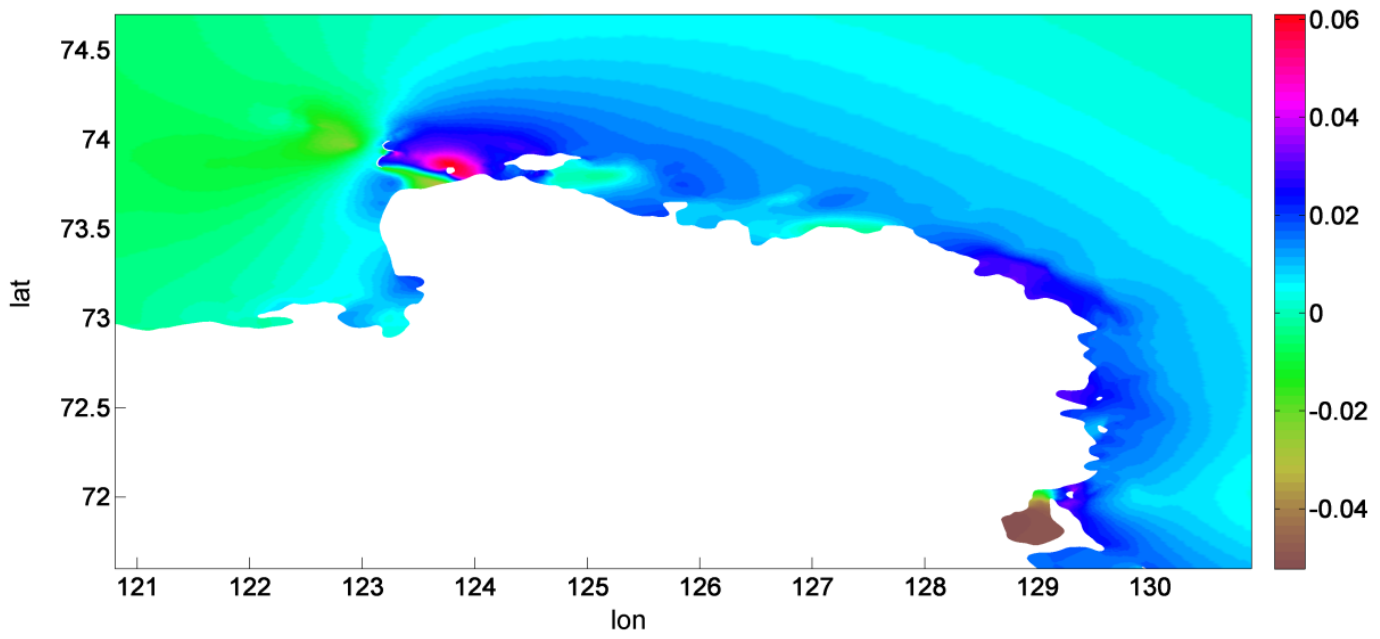

Fig. 9. a) The difference between GEBCO bathymetry and additional bathymetric data from digitized Soviet map, [m],

b) The differences between amplitudes of the $M_{2}$ in simulations based on GEBCO and modified bathymetry, [m]. 


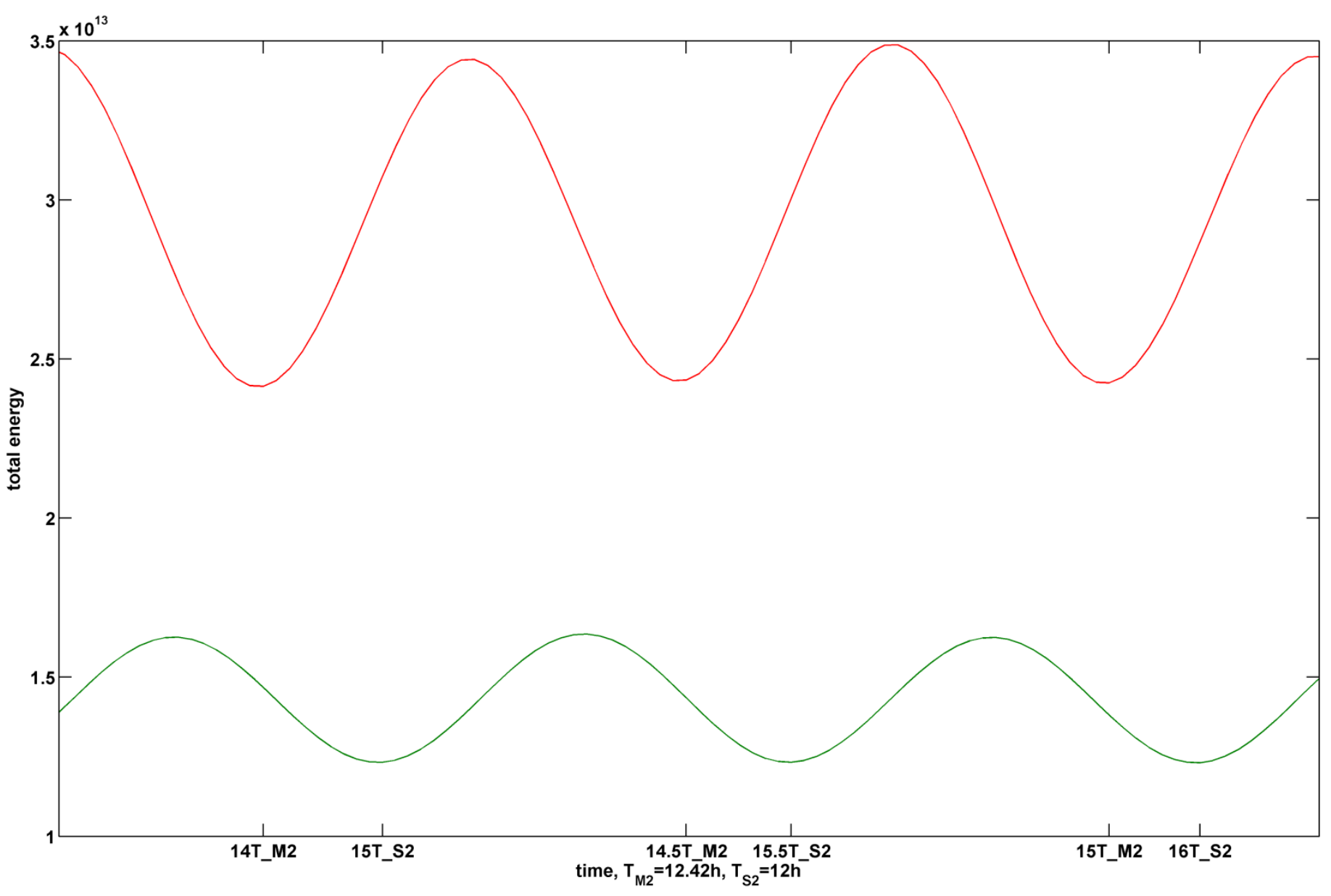

Fig. 10. The total energy, [J]: in red - for the $M_{2}$ constituent, in green - for the $S_{2}$ constituent.

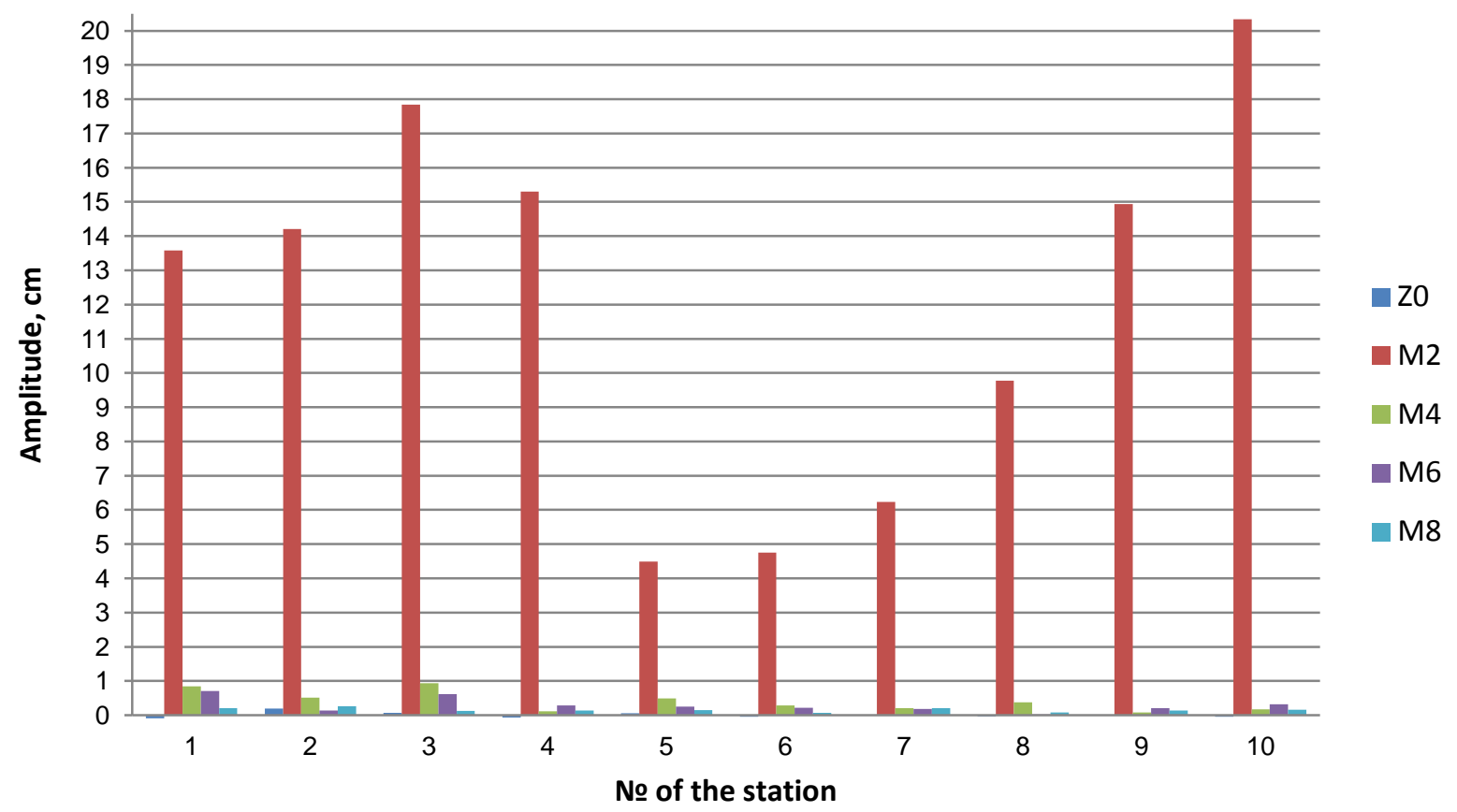

Fig. 11. The amplitudes of $M_{2}, M_{4}, M_{6}, M_{8}$ harmonics and $Z_{0}$ at all coastal stations. 

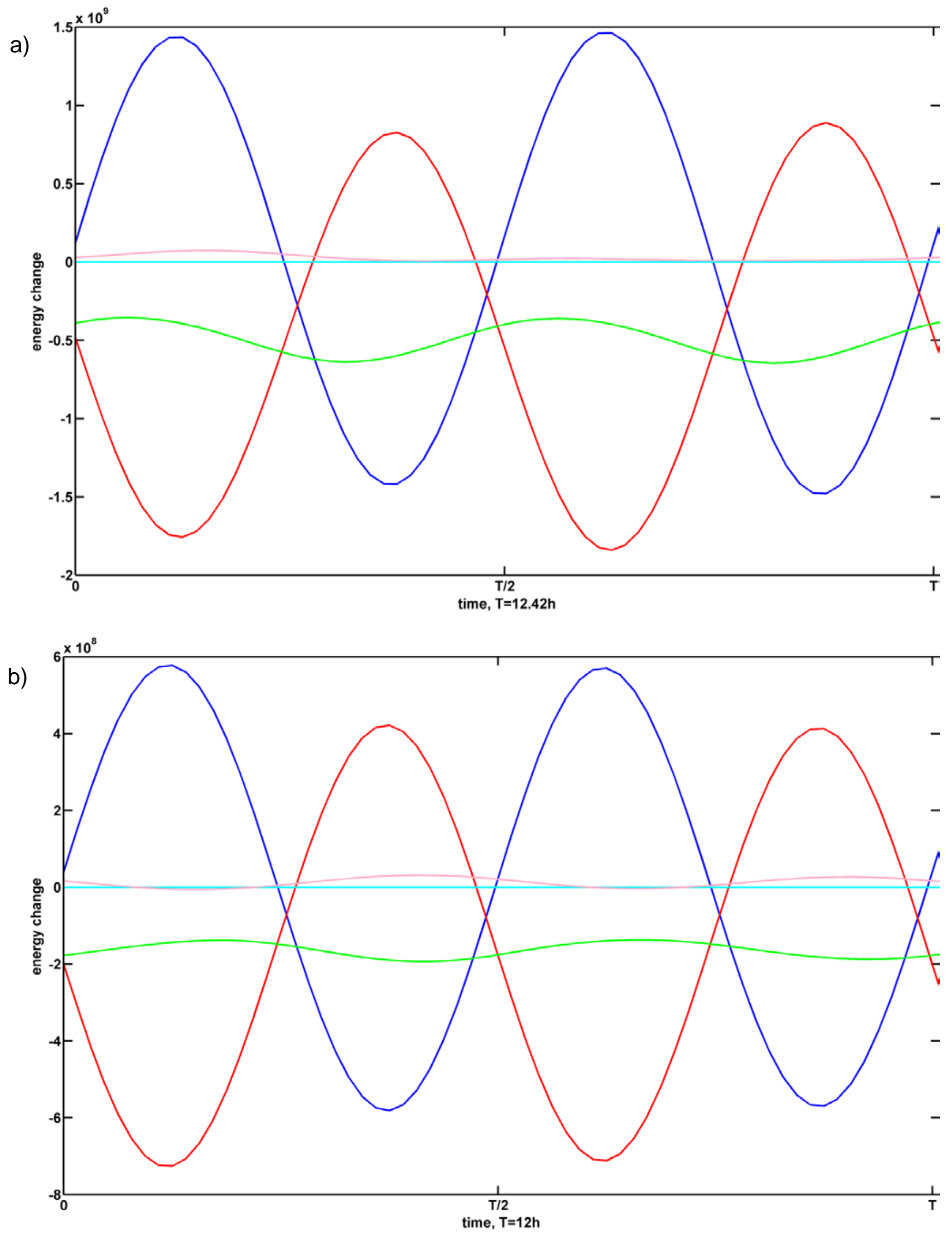

Fig. 12. Energetic budget, [W], in blue - energy change in time, in red - flow through the open boundaries, in green - bottom friction, in cyan - horizontal turbulent viscosity, in pink - the imbalance:
a) $M_{2}$ constituent
b) $S_{2}$ constituent 

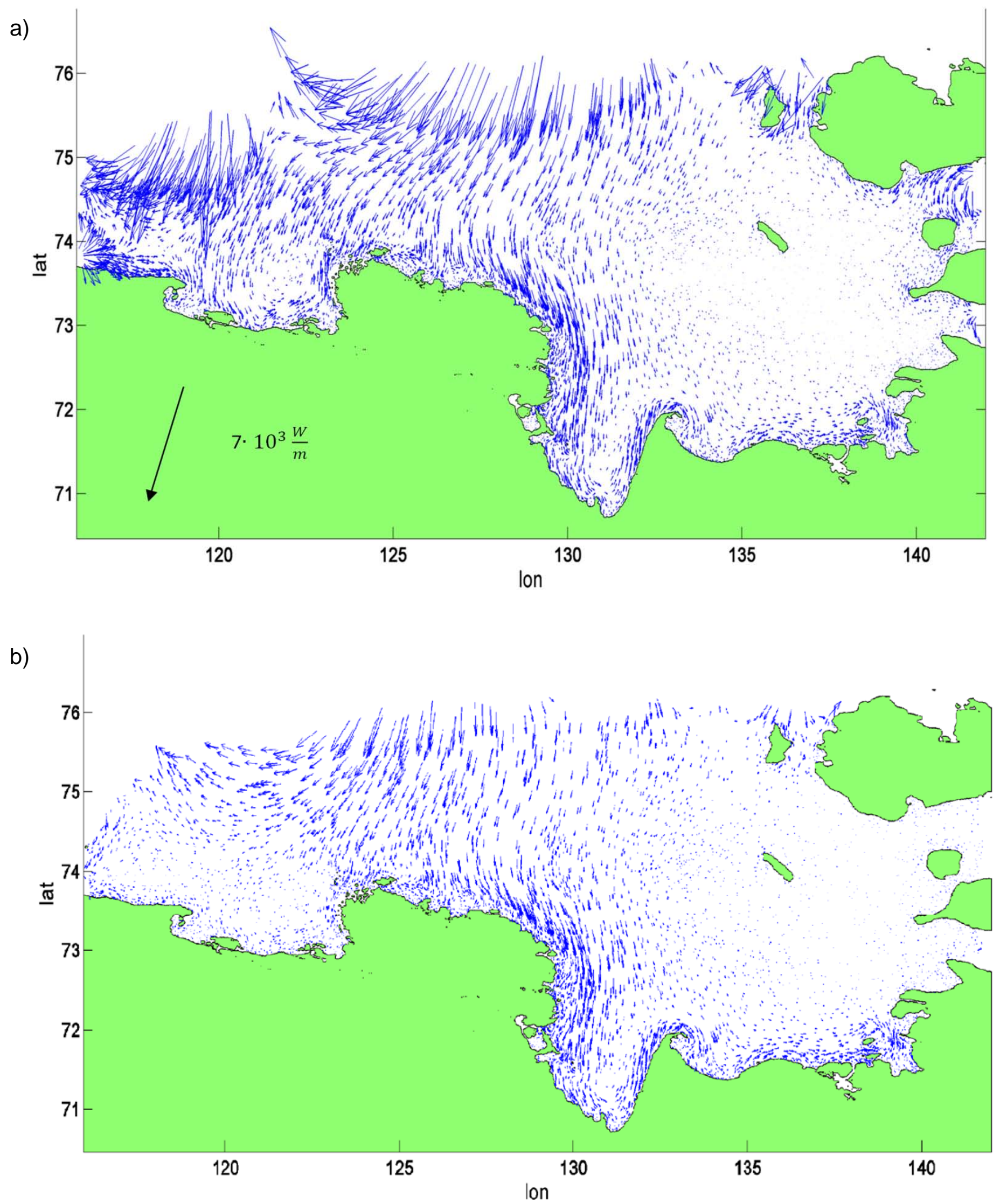

Fig. 13. The flux of tidal energy $\left(E_{\lambda}, E_{\theta}\right)$ for the $M_{2}(\mathrm{a})$ and $S_{2}$ (b) constituents. The vectors are shown for every 90th point of the instructed grid. 